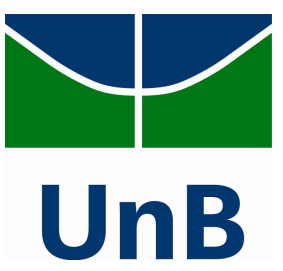

Universidade de Brasília Instituto de Ciências Exatas Departamento de Matemática Programa de Mestrado Profissional em Matemática em Rede Nacional

\title{
Algoritmo da divisão de Euclides
}

\section{Susiane Bezerra Caixeta}

Brasília 


\section{Susiane Bezerra Caixeta}

\section{Algoritmo da divisão de Euclides}

Dissertação apresentada ao Departamento de Matemática da Universidade de Brasília, como parte dos requisitos para obtenção do grau de Mestre.

Orientador: Profa. Dra. Aline Gomes da Silva Pinto

Brasília

2016 
.Universidade.de Brasília

Instituto de Ciências Exatas

Departamento de Matemática

\title{
Algoritmo da Divisão de Euclides
}

\author{
por \\ Susiane Bezerra Caixeta * \\ Dissertação apresentada ao Departamento de Matemática da Universidade de \\ Brasília, como parte dos requisitos do "Programa" de Mestrado Profissional em
} Matemática em Rede Nacional - PROFMAT, para obtenção do grau de:

\section{MESTRE}

Brasília, 25 de maio de 2016.

Comissão Examinadora:
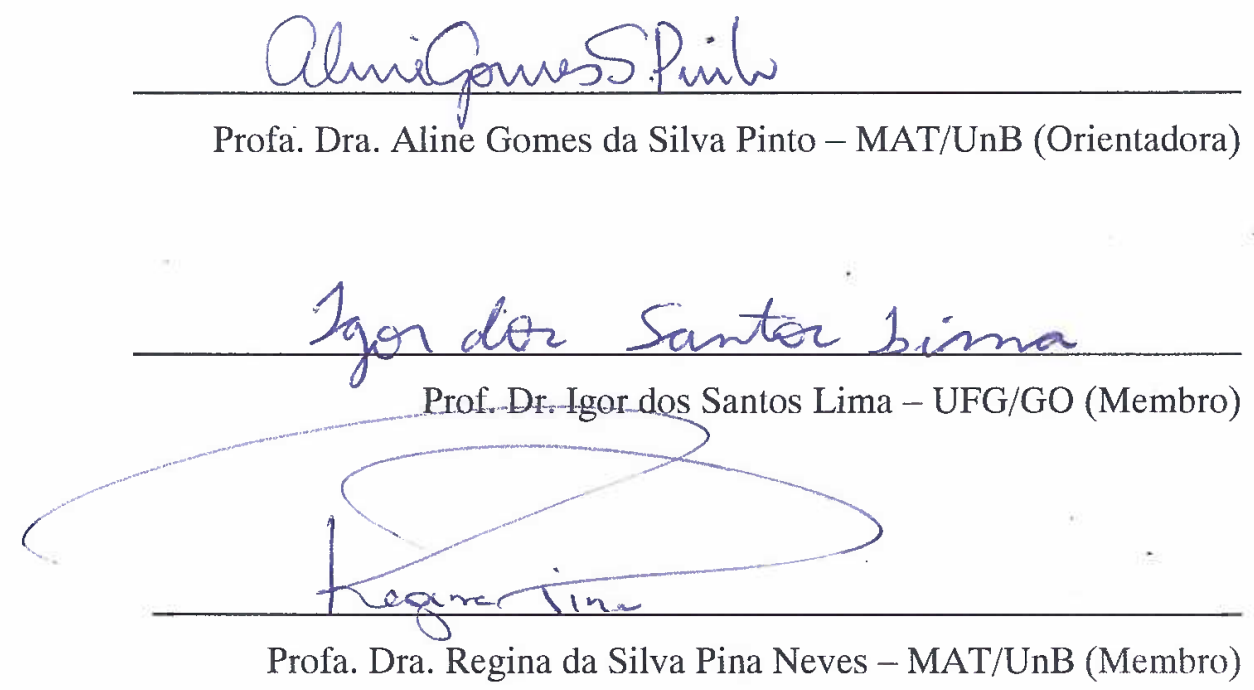

* O autor foi bolsista CAPES durante a elaboração desta dissertação 
Ficha catalográfica elaborada automaticamente, com os dados fornecidos pelo(a) autor(a)

Caixeta, Susiane Bezerra

Algoritmo da divisão de Euclides / Susiane

Bezerra Caixeta; orientador Aline Gomes da Silva Pinto. -- Brasília, 2016.

$80 \mathrm{p}$.

Dissertação (Mestrado - Mestrado Profissional em Matemática) -- Universidade de Brasília, 2016.

1. Algoritmo da divisão de Euclides. 2. Números Naturais. 3. Números Inteiros. 4. Problema do calendário. 5. Problema dos três marinheiros. I. Pinto, Aline Gomes da Silva, orient. II. Título. 
Todos os direitos reservados. É proibida a reprodução total ou parcial deste trabalho sem a autorização da universidade, do autor e do orientador.

Susiane Bezerra Caixeta cursou a licenciatura em Matemática pela Universidade de Brasília (UnB) no período de 2006 a 2010. 
Dedico este trabalho a minha filha, Karina, que mesmo aos 3 anos de idade sempre teve a compreensão e a paciência para que eu pudesse estudar e elaborar o mesmo. Dedico também ao meu querido companheiro, meu esposo Carlos, que nesses 12 anos de cumplicidade sempre me apoiou e me incentivou em tudo que almejei. 


\section{Agradecimentos}

Agradeço primeiramente a Deus por ter sido muito benevolente comigo. Sempre me considerei uma pessoa sortuda, mas sei que tudo que aconteceu foi por meio das Suas infinitas bênçãos.

Agradeço ao meu pai, Orci, pelo amor e carinho, e por ser o melhor exemplo de caráter e inteligência que poderia existir. Agradeço a minha mãe, Suely, que sempre me mostrou a importância do trabalho e de como a simpatia e a empatia são importantes na nossa vida. Agradeço a minha irmã, Suelen, pelo companheirismo e apoio dados desinteressadamente. Agradeço a todos os meus familiares, que mesmo não contribuindo diretamente nesse trabalho, por fazerem parte da minha vida.

Aos meus colegas e amigos do PROFMAT 2014. Nesses dois anos em que nos encontramos durante as aulas ou nas comemorações (lanches e chás de fraldas) formamos uma amizade tão bonita e tão sincera que jamais esquecerei. Me sinto privilegiada por ter feito parte dessa turma. Obrigada a todos!

Um grande agradecimento a minha orientadora, Dra. Aline, pela paciência, dedicação e por me alentar em momentos que achei que não conseguiria. Saiba que sua inteligência e conhecimento sempre me inspiraram, desde o período da graduação.

Agradeço aos professores do Departamento de Matemática da UnB, que fizeram parte da minha formação no PROFMAT: Lineu Neto, Ary Vasconcelos, Diego Marques, Angel Rodolfo Baigorri, Helder Matos, Carlos Alberto, Mauro Rabelo, Kellcio Oliveira e o coordenador Rui Seimetz. Obrigada por me incentivarem a buscar o conhecimento sempre mais!

Agradeço também à CAPES pelo apoio financeiro a este trabalho.

Enfim, agradeço a todos que de alguma forma contribuíram para a minha formação acadêmica, e também na elaboração desse trabalho e na conclusão do PROFMAT. 


\section{Resumo}

O Algoritmo da divisão de Euclides, bem como todos os conteúdos matemáticos apresentados na Educação Básica, devem ser lecionados de forma contextualizada. Isso favorece o estudante, de forma que o mesmo tenha um aprendizado mais eficiente. Esta dissertação visa fundamentar teoricamente a parte matemática necessária para a discussão, aperfeiçoando o conhecimento matemático do professor no assunto e favorecendo a sua formação continuada. Para isso, serão construídos o conjunto dos números naturais e o conjunto dos números inteiros, além de discorrer sobre divisibilidade. Todos esses tópicos serão compostos de uma linguagem matemática formal. Além disso, esta dissertação propõe atividades que relacionem situações-problema do cotidiano com o tema, de forma que os estudantes possam descobrir por meio de discussões em grupo a resolução dos mesmos. Dessa forma, são propostas atividades que seguem uma tendência metodológica de ensino-aprendizagem em educação matemática conhecida como resolução de problemas.

\section{Palavras-chave}

Números naturais, números inteiros, algoritmo da divisão de Euclides, calendário, o problema dos três marinheiros, resolução de problemas. 


\begin{abstract}
Euclid's division Algorithm as well as all mathematical content presented in basic education should be taught in context. This favors the student, so that it has a more efficient learning. This work aims to present the theory involved in the discussion of the Euclid's algorithm, in other to give support to Mathematic teachers of fundamental school to improve their knowledge about the integer numbers. For this, we present the formal construction of the natural numbers and integer numbers and a formal proof of Euclid's division algoritm. In this dissertation, we also aim to propose activities that contextualize the theme in everyday situations, so that teachers can motivate the students to discuss some everyday problems involving Euclid's algorithm, working in groups. The activities follow a methodological tendency in math education known as problem solving.
\end{abstract}

\title{
Keywords
}

Natural numbers, integers, Euclid's division algorithm, calendar, the problem of the three sailors, problem solving. 


\section{Sumário}

$\begin{array}{ll}\text { Introdução } & 12\end{array}$

1 Histórico $\quad 15$

1.1 Primórdios da operação de divisão . . . . . . . . . . . . . . . . . . . 15

1.2 Euclides e Os Elementos . . . . . . . . . . . . . . . . . . 17

1.3 Números Naturais e Números Inteiros . . . . . . . . . . . . . 18

2 Construção dos Números Naturais $\quad 19$

2.1 Axiomas de Peano . . . . . . . . . . . . . . . . 19

2.2 Adição de Números Naturais . . . . . . . . . . . . . . . . . 21

2.3 Multiplicação de Números Naturais . . . . . . . . . . . . . . . . . . . . . . . . . . . . . . . . . .

2.4 Relação de ordem em $\mathbb{N} \ldots \ldots \ldots . \ldots . \ldots . . \ldots 27$

3 Construção dos Números Inteiros $\quad 32$

3.1 Relação de equivalência . . . . . . . . . . . . . . . . . 32

3.2 Adição de Números Inteiros . . . . . . . . . . . . . . . . . . . . . . . . . . . . . . . . . . . . . . . . . .

3.3 Multiplicação de Números Inteiros . . . . . . . . . . . . . . . 37

3.4 Relação de ordem em $\mathbb{Z} \ldots \ldots \ldots \ldots$. . . . . . . . . . 41

$\begin{array}{llr}4 \text { Divisibilidade } & 48\end{array}$

4.1 Divisão de Números Inteiros . . . . . . . . . . . . . . . . 48

4.2 Algoritmo da Divisão . . . . . . . . . . . . . . . . . . 51

5 Atividades Propostas 53

5.1 Atividade 1: Matemática e o Calendário . . . . . . . . . . 53

5.1 .1 História do Calendário . . . . . . . . . . . . . . 53 
5.1.2 Atividade relacionando o Calendário Gregoriano com o Algoritmo da divisão de Euclides . . . . . . . . . . . . 55

5.2 Atividade 2: A História dos Três Marinheiros . . . . . . . . . 59

5.2 .1 O Homem que Calculava - Malba Tahan . . . . . . . . . 59

5.2.2 Atividade relacionando a história dos Três Marinheiros com o Algoritmo da divisão de Euclides . . . . . . . . . . . . 61

$\begin{array}{ll}\text { Considerações Finais } & 77\end{array}$

$\begin{array}{ll}\text { Referências Bibliográficas } & 79\end{array}$ 


\section{Introdução}

O objetivo principal dessa dissertação é propor aos professores um material de estudo bem fundamentado sobre o Algoritmo da divisão de Euclides, bem como atividades contextualizadas e dinâmicas a serem aplicadas aos estudantes.

Infelizmente, muitos estudantes alcançam o sexto ano do ensino fundamental sem o domínio satisfatório da operação de divisão. Poucos aplicam o Algoritmo da divisão, mas o fazem de forma mecanizada, sem compreender o seu real significado. Por conseguinte, a maioria dos estudantes não conseguem resolver situações-problema do cotidiano que envolvem o tema.

Sou professora de matemática da Secretaria de Estado de Educação do Distrito Federal (SEEDF), e durante a minha experiência em sala, ao lecionar sobre o tema, pude notar essa dificuldade por parte dos estudantes. Por vezes, eles mesmos falavam sobre isso, afirmando que não tinham entendido como era feita a operação de divisão e/ou não sabiam o porquê da utilização dos passos ensinados em sala para esse fim. Essa sequência de passos é o que chamamos de Algoritmo da divisão de Euclides, e essa noção geralmente é apresentada aos estudantes no $4^{\circ}$ ano do ensino fundamental.

Mesmo com essa apresentação, quando os estudantes alcançam o $6^{\circ}$ ano do ensino fundamental, nota-se a grande dificuldade com o domínio e a utilização desses conceitos e regras. Isso pode estar ocorrendo devido às grandes mudanças que ocorrem do $5^{\circ}$ para o $6^{\circ}$ ano do ensino fundamental. Nessa fase, os estudantes saem dos anos iniciais, cujos professores são pedagogos, para ingressarem nos anos finais, cujos professores são licenciados em suas respectivas áreas. Com isso, há um grande desafio posto aos professores que recebem esses estudantes no $6^{\circ}$ ano do ensino fundamental, pois a adaptação deve ocorrer de modo progressivo e satisfatório, tanto para os estudantes quanto para o professor. O objetivo das atividades propostas é facilitar essa adaptação.

Para cumprir seus propósitos de formar cidadãos conscientes e preparados para o mundo do trabalho e a convivência social, os Parâmetros Nacionais Curriculares em 
Matemática ([?], p. 60), "indicam aspectos novos no estudo dos números e operações, privilegiando o desenvolvimento do sentido numérico e a compreensão de diferentes significados das operações". Dessa forma, serão propostas atividades com esse enfoque, nas quais o estudante usará o Algoritmo da divisão de Euclides para a resolução de situações-problema. Além disso, por meio da mediação do professor, o estudante poderá entender os motivos dessa utilização e ainda relacioná-los com outras situações.

Essa dissertação será composta de cinco capítulos. O primeiro consiste em uma exposição do contexto histórico que abrange o Algoritmo da divisão de Euclides. O segundo capítulo fará a fundamentação teórica sobre o tema, com a construção do conjunto dos números naturais por meio dos Axiomas de Peano. Dando sequência, no terceiro capítulo será trabalhada a construção do conjunto dos números inteiros. O quarto capítulo finalizará a fundamentação teórica argumentando a respeito da divisibilidade. Todos os capítulos que abrangem a fundamentação teórica terão uma linguagem matemática formal, composta de axiomas e definições, além de teoremas e proposições com suas respectivas demonstrações. E por fim, no quinto capítulo serão propostas atividades que objetivam que os estudantes compreendam a operação de divisão de forma satisfatória.

A finalidade das atividades propostas é o trabalho cooperativo entre os estudantes, ou seja, as resoluções devem ser discutidas e avaliadas por todos que compõem o grupo. As reflexões sugeridas visam instigar discussões para facilitar o entendimento dos problemas propostos, buscando utilizar o Algoritmo da divisão de Euclides na resolução. Uma vez discutido e utilizado na resolução dos problemas propostos, o tema poderá ser relacionado com outras situações cotidianas de modo mais conveniente.

Procedentes de atividades aplicadas para ensino médio, as atividades propostas nessa dissertação foram reformuladas para serem aplicadas no $6^{\circ}$ e $7^{\circ}$ anos do ensino fundamental. Uma das propostas sugeridas foi adaptada da atividade Desvendando o Calendário de Paques ([?]), que envolve o Algoritmo da divisão de Euclides e o calendário, utilizando o conjunto dos números inteiros. A atividade foi adaptada para que apenas o conjunto dos números naturais fosse necessário. A outra proposta sugerida foi inspirada em uma história do livro O Homem que Calculava ([?], p. 147-148). Essa atividade foi baseada na História dos Três Marinheiros que geralmente é trabalhada no ensino médio e utiliza sistema de equações na resolução. A atividade foi adaptada para que apenas o Algoritmo da divisão de Euclides fosse utilizado, visto que o problema envolve várias divisões com restos diferentes de zero.

Assim sendo, essa dissertação proporciona um estudo aprofundado do tema para os 
professores, e a partir desse estudo a possibilidade da mediação do mesmo em sala de aula com os estudantes, realizando as modificações necessárias quanto a linguagem. 


\section{Capítulo 1}

\section{Histórico}

Em qualquer conteúdo matemático a abordagem histórica se faz importante. Entender as origens e a evolução de um determinado assunto pode facilitar a sua elucidação, tornando-o mais interessante. Além disso, essa abordagem ajuda a entender que a matemática não é algo acabado, logo, é uma construção humana (sócio-histórica).

A seguir serão descritos alguns assuntos importantes da história da matemática que envolvem os assuntos pertinentes ao tema. Esses assuntos serão divididos em três tópicos. O primeiro tópico será sobre os primórdios da operação de divisão, que descreverá como era feita essa operação antes do algoritmo utilizado atualmente. O segundo tópico terá alguns pontos sobre Euclides e uma de suas obras, conhecida como uma das mais importantes da matemática, Os Elementos. O terceiro tópico pontuará alguns registros antigos acerca de números naturais e inteiros. Esse capítulo foi baseado em Aaboe ([?]), em Boyer ([?]) e em Eves ([?]).

\subsection{Primórdios da operação de divisão}

Segundo Boyer ([?], p. 9-11), um dos registros mais extensos de natureza matemática que resistiu ao desgaste do tempo é o Papiro Rhind (2000 a 1800 a.c.). Também conhecido como Papiro Ahmes (devido a um escriba que o copiou por volta de 1650 a.c.) esse documento egípcio mostra como era realizada uma operação de divisão na época. A operação aritmética fundamental no Egito era a adição, e como a multiplicação, a divisão também era operada através de sucessivas "duplações". 
Segundo Boyer ([?], p. 16), o Papiro Rhind está entre um dos mais antigos registros matemáticos, cerca de mil anos antes do nascimento da matemática grega. E como todos os estágios da matemática egípcia eram baseados na operação de adição, isso se tornou "uma desvantagem que conferia aos cálculos dos egípcios um peculiar primitivismo, combinado com uma ocasional e assombrosa complexidade".

A seguir temos um exemplo de como a operação de divisão era efetivamente realizada pelos egípcios, segundo Eves ([?], p. 72-73).

E para, digamos, dividir 753 por 26, dobramos sucessivamente o divisor 26 até o ponto em que o próximo dobro exceda o dividendo 753. O procedimento está exposto abaixo.

Ora, como

\begin{tabular}{rr}
1 & 26 \\
2 & 52 \\
$* 4$ & 104 \\
$* 8$ & 208 \\
$* 16$ & 416 \\
\hline 28 &
\end{tabular}

$$
\begin{aligned}
753 & =416+337 \\
& =416+208+129 \\
& =416+208+104+25
\end{aligned}
$$

vemos, observando as linhas com asteriscos na coluna acima, que o quociente é $16+8+4=28$ e o resto é 25 . O processo egípcio de multiplicação e divisão não só elimina a necessidade de aprender a tabuada de multiplicação, como também se amolda tanto ao ábaco que perdurou enquanto esse instrumento esteve em uso e mesmo depois.

No exemplo acima podemos observar que a construção da tabela com as sucessivas duplações era composta por duas colunas. A primeira indicava o número de vezes que o divisor, no caso o 26, estava sendo multiplicado. Dobrar um número é multiplicá-lo por 2. Se dobrarmos novamente, estaremos multiplicando esse número por 4, e assim sucessivamente. A segunda coluna indicava o valor dessa multiplicação. Assim, os números com os asteriscos na primeira coluna indicava quantas vezes o 26 "cabia" no dividendo, no caso os 753. Assim, o resultado da divisão foi 28, com resto 25.

Segundo Aaboe ([?], p. 9-21), além do Papiro Rhind, foram encontrados no final do século dezenove durante escavações em colinas na Mesopotâmia, tabletes (tábuas) 
de argila com a escrita cuneiforme, alguns datando de 1700 a.c.. Através de estudos feitos nesses tabletes constatou-se que eram registros da matemática babilônica. Com isso, descobriu-se que o sistema de numeração babilônico era posicional como o atual, porém, ao invés de ser um sistema de numeração decimal (na base 10), o mesmo era sexagesimal (na base 60). Foram encontradas também listas de multiplicações e listas de números com os seus respectivos recíprocos (inversos). Segundo Boyer ([?], p. 22);

É claro que as operações aritméticas fundamentais eram tratadas pelos babilônicos de modo não muito diferente do usado hoje, e com facilidade comparável. A divisão não era efetuada pelo incômodo processo de duplicação dos egípcios, mas por uma fácil multiplicação do dividendo pelo inverso do divisor, usando os itens apropriados nas tabelas.

Mais detalhes e curiosidades a respeito de como ocorreram essas descobertas da matemática babilônica por meio dos tabletes citados podem ser apreciadas em Aaboe ([?], p. 9-42).

Outros modos diferentes de como era realizada a operação de divisão na antiguidade podem ser encontrados em Neves ([?], p. 24-34).

Com isso, segundo Neves ([?], p. 34), podemos concluir que a prática da divisão nas civilizações antigas, conforme registros históricos, "apresentam indícios do raciocínio multiplicativo e proporcional para a resolução de muitas situações", além da "presença de problemas (em campo) ou criados para fins de instrução" e, dessa forma, surgiu "a criação de procedimentos (algoritmos) para a sua resolução".

\subsection{Euclides e $O s$ Elementos}

Segundo Boyer, ([?], p. 74-75), por volta de 306 a.c., Ptolomeu I criou em Alexandria uma escola (ou instituto) chamado de Museu, "insuperado em seu tempo". Euclides foi um dos professores do grupo de sábios (os mais reconhecidos da época) contratados para lecionar no Museu. Por isso, ficou conhecido como Euclides de Alexandria, apesar de algumas vezes ser chamado erroneamente de Euclides de Megara (um discípulo de Sócrates). Apesar do desconhecimento sobre sua vida, Euclides é considerado como o autor do texto de matemática mais bem sucedido de todos os tempos, Os Elementos de Euclides.

Ao contrário do que muitos imaginam Os Elementos não trata apenas de geometria, mas há também uma exposição em ordem lógica dos assuntos básicos da matemática 
elementar (aritmética ou teoria dos números, geometria e álgebra). Dos treze livros ou capítulos que compõe essa obra três deles falam sobre teoria dos números, os de número VII, VIII e IX.

\subsection{Números Naturais e Números Inteiros}

Segundo Boyer ([?], p. 160), indícios da presença dos números negativos foram encontrados pela primeira vez em uma obra de Brahmagupta (viveu em 628) por meio de uma aritmética sistematizada tanto dos números inteiros como do zero.

A noção de números negativos foi encontrada, segundo Boyer ([?], p. 145-147) no ábaco chinês, que diferente do árabe, possuia "duas coleções de barras — uma vermelha para os coeficientes positivos ou números e um preta para os negativos." (os ábacos mais modernos conhecidos na China são do século dezesseis, mais os originários parecem ter sido usados a mil anos atrás).

Segundo Boyer ([?], p. 436-437), Giuseppe Peano (1858 - 1932) foi um dos matemáticos interessados em lógica matemática mais conhecidos do século dezenove. Sua elaboração dos Axiomas de Peano, em 1889, foi baseada em um simbolismo puro formal, ou seja, desconsiderou a descrição em palavras que causavam tantas ambiguidades e hipóteses ocultas (método postulacional). A importância da elaboração dessa obra não é somente pela formalização da construção dos números naturais, mas também por embasar construções formais da álgebra e da análise, como o Princípio de indução. 


\section{Capítulo 2}

\section{Construção dos Números Naturais}

Nesse capítulo construiremos o conjunto dos números naturais. Inicialmente enunciaremos os Axiomas de Peano. Em seguida, as demonstrações serão baseadas no Axioma 3, conhecido como Princípio de Indução. Definiremos as operações de adição e multiplicação, com suas respectivas propriedades. Continuando o capítulo, estabeleceremos uma relação de ordem nesse conjunto. Além disso, falaremos sobre o Princípio da Boa Ordem: qualquer subconjunto não vazio de $\mathbb{N}$ tem um menor número. E finalizando o capítulo mostraremos a equivalência entre o Princípio de Indução e o Princípio da Boa Ordem. Toda construção será baseada em definições e axiomas além de teoremas e proposições com suas respectivas demonstrações. Esse capítulo foi baseado em Ferreira ([?]), em Milies ([?]) e em Shokranian ([?]). A construção considerará o zero como número natural, mas para estudar uma construção em que o zero não está incluso no conjunto dos números naturais basta consultar Lima ([?]).

\subsection{Axiomas de Peano}

Utilizando conceitos matemáticos conhecidos, como conjunto e função, vamos expor os axiomas de Peano a seguir:

Existe um conjunto $\mathbb{N}$ e uma função $s: \mathbb{N} \rightarrow \mathbb{N}$ que admite os seguintes axiomas:

Axioma 1. s é injetora, ou seja, elementos distintos do domínio têm imagens diferentes. 
Axioma 2. Existe um elemento em $\mathbb{N}$, denotado por 0 (chamado de zero) tal que $0 \notin \operatorname{Im}(s)$.

Axioma 3. Seja $A$ um subconjunto de $\mathbb{N}$ tal que:

i) $0 \in A$;

ii) $n \in A \Rightarrow s(n) \in A$.

Então $A=\mathbb{N}$.

O conjunto $\mathbb{N}$ é chamado de Conjunto dos Números Naturais. O Axioma 3 definido acima é conhecido como o Princípio da Indução Matemática, ou Princípio da Indução Completa, ou simplesmente Princípio de Indução.

Definiremos agora uma função sucessor e em seguida mostraremos algumas de suas características, expostas no Teorema a seguir. Esse passo é muito importante para definirmos as operações em $\mathbb{N}$.

Definição 2.1.1. Dizemos que $s: \mathbb{N} \rightarrow \mathbb{N}$ é uma função sucessor quando é injetora e cada elemento $x$ do domínio é associado ao elemento $x+1$ do contradomínio, sendo $s(0)=1$ e $0 \notin \operatorname{Im}(s)$.

Teorema 2.1.1. Se $s: \mathbb{N} \rightarrow \mathbb{N}$ é a função sucessor, então, tem-se:

i) $s(n) \neq n$, para todo $n \in \mathbb{N}$, ou seja, nenhum número natural é sucessor de si mesmo;

ii) $\operatorname{Im}(s)=\mathbb{N} \backslash\{0\}$, ou seja, o zero é o único natural que não é sucessor de nenhum número natural.

Demonstração. i) Seja $A$ o subconjunto de $\mathbb{N}$ tal que

$$
A=\{n \in \mathbb{N}: s(n) \neq n\} .
$$

Temos que $0 \in A$, pois $s(0) \neq 0$, já que $0 \notin \operatorname{Im}(s)$ pelo Axioma 2. Pela definição do conjunto $A$ temos que

$$
k \in A \Leftrightarrow s(k) \neq k .
$$

Aplicando $s$ em ambos os membros de $s(k) \neq k$, obtemos $s(s(k)) \neq s(k)$, já que $s$ é injetora pelo Axioma 1. Assim, $s(k) \in A$. Logo, como temos

$$
0 \in A
$$

e

$$
k \in A \Rightarrow s(k) \in A,
$$


pelo Axioma 3, concluímos que $A=\mathbb{N}$.

ii) Tomemos o conjunto $A=\mathbb{N} \cup \operatorname{Im}(s)$. Note que $A \subset \mathbb{N}$. Temos que $0 \in A$ e se $k \in A$ então $s(k) \in \operatorname{Im}(s)$, assim $s(k) \in A$. Pelo Axioma 3 temos que $A=\mathbb{N}$, e como $0 \notin \operatorname{Im}(s)$, pelo Axioma 2, então $\operatorname{Im}(s)=\mathbb{N} \backslash\{0\}$.

Notação 2.1.1. $\mathbb{N} \backslash\{0\}=\mathbb{N}^{*}$.

Definição 2.1.2. Dado um número natural $n \neq 0$, o número natural $m$ tal que $s(m)=$ $n$ chama-se antecessor de $n$, e $n$ chama-se sucessor de $m$.

\subsection{Adição de Números Naturais}

Definição 2.2.1. A adição de números naturais, $m$ e $n$, é representada por $m+n$ e definida recursivamente como:

i) $m+0=m$;

ii) $m+s(n)=s(m+n)$.

Proposição 2.2.1. A adição de números naturais está bem definida em $\mathbb{N}$.

Demonstração. Seja $A$ o conjunto dos números naturais $n$ cujas somas $m+n$ estão bem definidas em $\mathbb{N}$. Pela condição i) da Definição ?? temos que $0 \in A$ pois $m=m+0 \in A$. Pela condição ii) também da Definição ?? temos que, se $m+n$ está bem definido, para todo $n \in \mathbb{N}$, então $m+s(n)=s(m+n)$ também está definido, ou seja,

$$
n \in A \Rightarrow s(n) \in A \text {. }
$$

Logo, pelo Axioma 3 a soma está definida em $\mathbb{N}$.

Definição 2.2.2. Indicaremos por 1 (lê-se um) o número natural que é sucessor de 0 , ou seja, $s(0)=1$.

Agora que já definimos a operação da adição em $\mathbb{N}$ e mostramos que está bem definida, vamos demonstrar a validade de suas propriedades.

Proposição 2.2.2. Para todo natural $m$, tem-se $s(m)=m+1$ e $s(m)=1+m$. Portanto $m+1=1+m$. 
Demonstração. Para mostrar a igualdade $s(m)=m+1$, basta observar que

$$
m+1=m+s(0)=s(m+0)=s(m) .
$$

Agora, para mostrar a igualdade $s(m)=1+m$, consideremos um conjunto

$$
A=\{m \in \mathbb{N}: s(m)=1+m\} .
$$

Note que $0 \in A$, pois $s(0)=1=1+0$. Tomando $m \in A$, mostraremos que $s(m) \in A$. De fato,

$$
s(m)=1+m \Rightarrow s(s(m))=s(1+m)=1+s(m) .
$$

Assim, $s(m) \in A$. Com isso, pelo Axioma 3, temos $A=\mathbb{N}$.

A partir daqui utilizaremos também a notação indo-arábica para os elementos em $\mathbb{N}$, ou seja, o sucessor de um número natural $m$ poderá ser indicado como $m+1=s(m)$.

Teorema 2.2.1. Sejam $m, n$ e $p$ números naturais quaisquer. São verdadeiras as seguintes afirmações:

i) Propriedade Associativa da Adição: $m+(n+p)=(m+n)+p$;

ii) Propriedade Comutativa da Adição: $m+n=n+m$;

iii) Lei do Cancelamento da Adição: $m+p=n+p \Rightarrow m=n$.

Demonstração. i) Fixando os números $m$ e $n$ utilizaremos indução em $p$. Tome o conjunto

$$
A_{(m, n)}=\{p \in \mathbb{N}: m+(n+p)=(m+n)+p\} .
$$

Temos que $0 \in A_{(m, n)}$, pois

$$
m+(n+0)=m+n=(m+n)+0 .
$$

Tomando um $k \in A_{(m, n)}$, ou seja, $m+(n+k)=(m+n)+k$, e utilizando a definição de adição em $\mathbb{N}$ temos que

$$
m+(n+s(k))=m+s(n+k)=s(m+(n+k))=s((m+n)+k)=(m+n)+s(k) .
$$

Logo, pelo Axioma 3, $A_{(m, n)}=\mathbb{N}$. Como $m$ e $n$ são quaisquer, então a propriedade associativa da adição em $\mathbb{N}$ está provada.

ii) Fixando o número $m$ qualquer provaremos por indução em $n$. Tome o conjunto

$$
A_{(m)}=\{n \in \mathbb{N}: m+n=n+m\} .
$$


Temos que $0 \in A_{m}$, pois

$$
m+0=m=0+m \text {. }
$$

Tomando $k \in A_{m}$, ou seja, $m+k=k+m$, e utilizando a Proposição ?? temos que $m+s(k)=s(m+k)=s(k+m)=(k+m)+1=1+(k+m)=(1+k)+m=s(k)+m$.

Logo, pelo Axioma 3, $A_{(m)}=\mathbb{N}$, e como $m$ é qualquer, a propriedade comutativa da adição em $\mathbb{N}$ está provada.

iii) Fixando os números $m$ e $n$ quaisquer e tomando um conjunto

$$
A_{(m, n)}=\{p \in \mathbb{N}: m+p=n+p \Rightarrow m=n\},
$$

provaremos por indução em $p$ que $A_{(m, n)}=\mathbb{N}$. Temos que $0 \in A_{(m, n)}$, pois

$$
m+0=n+0 \Rightarrow m=n .
$$

Tomando $k \in A_{(m, n)}$, ou seja, $m+k=n+k \Rightarrow m=n$ e lembrando que $s$ é injetora, pelo Axioma 1, temos que

$$
m+s(k)=n+s(k) \Rightarrow s(m+k)=s(n+k) \Rightarrow m+k=n+k \Rightarrow m=n .
$$

Logo, pelo Axioma 3, $A_{(m, n)}=\mathbb{N}$, e como $m$ e $n$ são quaisquer, a lei de cancelamento da adição em $\mathbb{N}$ está provada.

Proposição 2.2.3. Suponha que exista $u \in \mathbb{N}$ tal que $m+u=m$, ou que $u+m=m$, para todo $m \in \mathbb{N}$. Então $u=0$, e este é o único elemento neutro para a operação de adição em $\mathbb{N}$.

Demonstração. Para um tal $u$ temos: $0=0+u=u$.

Proposição 2.2.4. Sejam $m, n \in \mathbb{N}$ tais que $m+n=0$. Então $m=n=0$.

Demonstração. Suponhamos que $n \neq 0$. Logo $n$ é sucessor de um número natural $n_{1}$, ou seja, $n=n_{1}+1$, assim:

$$
0=m+n=m+\left(n_{1}+1\right)=\left(m+n_{1}\right)+1=s\left(m+n_{1}\right) .
$$

Mas isso é um absurdo, pois pelo Axioma 2 o zero não é sucessor de número algum. Logo, $n=0$. Assim,

$$
0=m+n=m+0=m
$$




\subsection{Multiplicação de Números Naturais}

Definição 2.3.1. A multiplicação de dois números $m$ e $n$ naturais é representada por $m \cdot n$ (ou $m n)$ e definida recursivamente como:

i) $m \cdot 0=0$;

ii) $m \cdot(n+1)=m n+m$.

A partir da Definição ?? mostraremos a validade das propriedades da multiplicação em $\mathbb{N}$.

Teorema 2.3.1. Sejam $m, n$ e $p$ números naturais quaisquer. São verdadeiras as seguintes afirmações:

i) $m n \in \mathbb{N}$, ou seja, a multiplicação está bem definida em $\mathbb{N}$.

ii) Elemento Neutro da Multiplicação: $1 \cdot n=n \cdot 1=n$.

iii) Propriedade Distributiva da Multiplicação em relação a Adição: $m \cdot(n+p)=$ $m n+m p$ e $(m+n) \cdot p=m p+n p$.

iv) Propriedade Associativa da Multiplicação: $m \cdot(n p)=(m n) \cdot p$.

v) $m n=0 \Rightarrow m=0$ ou $n=0$.

vi) Propriedade Comutativa da Multiplicação: $n m=m n$.

Demonstração. i) Seja $A$ o conjunto de números naturais tais que a multiplicação entre quaisquer dois elementos desse conjunto é um número natural. Pela Definição ?? obtemos que $0 \in A$, pois dado um $m \in \mathbb{N}$ qualquer, $m \cdot 0=0 \in \mathbb{N}$, $\log 0 \in A$. Suponhamos que um natural $n$ qualquer esteja em $A$, logo, dado $m \in \mathbb{N}$ temos $m n \in \mathbb{N}$. Queremos mostrar que $s(n)=n+1 \in A$, ou seja $m \cdot(n+1) \in \mathbb{N}$. Pela Definição ?? temos

$$
m \cdot(n+1)=m n+m .
$$

Por hipótese, $m n \in \mathbb{N}$ e temos $m \in \mathbb{N}$, $\log m n+m \in \mathbb{N}$, pois a soma está bem definida em $\mathbb{N}$. Assim, pelo Axioma $3, A=\mathbb{N}$ e a multiplicação está bem definida em $\mathbb{N}$.

ii) Queremos mostrar que $n \cdot 1=n$. Temos que:

$$
n \cdot 1=n \cdot(0+1)=n \cdot 0+n \cdot 1=0+n=n .
$$

Assim, $n \cdot 1=n$. Por outro lado, para $n=0$ temos que $1 \cdot 0=0$. Suponhamos que a igualdade $1 \cdot n=n$ vale para um $n$ natural qualquer. Queremos mostrar que vale para $n+1$, ou seja, $1 \cdot(n+1)=n+1$. De fato, utilizando a Definição ??,

$$
1 \cdot(n+1)=1 \cdot n+1 \cdot 1=n+1 .
$$


Assim, pelo Axioma 3, a afirmação

$$
1 \cdot n=n \cdot 1=n
$$

é válida, para todo $n \in \mathbb{N}$.

iii) Primeiro vamos mostrar que $m \cdot(n+p)=m n+m p$. Sejam $m, n$ números naturais quaisquer e considere o conjunto

$$
A=\{p \in \mathbb{N}: m \cdot(n+p)=m n+m p\}
$$

Temos que $0 \in A$, pois

$$
m \cdot(n+0)=m \cdot n=m n+0=m n+m \cdot 0 .
$$

Suponhamos que $q \in A$, ou seja, $m \cdot(n+q)=m n+m q$. Queremos mostrar que $q+1 \in A$, ou seja,

$$
m \cdot(n+(q+1))=m n+m \cdot(q+1)=m n+(m q+m)
$$

Temos

$$
m \cdot(n+(q+1))=m \cdot(n+s(q))=m \cdot s(n+q)=m \cdot((n+q)+1) .
$$

Usando a Definição ??, obtemos

$$
m \cdot((n+q)+1)=m \cdot(n+q)+m
$$

Agora, usando a hipótese obtemos

$$
m \cdot(n+q)+m=(m n+m q)+m .
$$

Como vale a lei associativa para adição, obtemos

$$
m \cdot(n+(q+1))=m n+(m q+m)
$$

como queríamos. Assim, pelo Axioma $3, A=\mathbb{N}$, ou seja, $m \cdot(n+p)=m n+m p$, para quaiquer $m, n, p \in \mathbb{N}$. Resta mostrar $(m+n) \cdot p=m p+n p$. Isso segue do propriedade comutativa que demonstraremos no item vi).

iv) Queremos mostrar que $m \cdot(n p)=(m n) \cdot p$. Sejam $m$ e $n$ números naturais quaisquer e considere o conjunto

$$
A=\{p \in \mathbb{N}: m \cdot(n p)=(m n) \cdot p\} .
$$


Temos que $0 \in A$, pois $m \cdot(n \cdot 0)=m \cdot 0=0$ e $(m n) \cdot 0=0, \operatorname{logo}, m \cdot(n \cdot 0)=(m n) \cdot 0$. Suponhamos que $q \in A$, ou seja, $m \cdot(n q)=(m n) \cdot q$. Queremos mostrar que $q+1 \in A$, ou seja, $m \cdot(n \cdot(q+1))=(m n) \cdot(q+1)$. Usando a Definição ?? e a propriedade distributiva da multiplicação temos

$$
m \cdot(n \cdot(q+1))=m \cdot(n q+n)=m \cdot(n q)+m n
$$

Utilizando a hipótese temos

$$
m \cdot(n q)+m n=(m n) \cdot q+m n .
$$

Como $(m n) \cdot q+m n=(m n) \cdot(q+1)$, obtemos $m \cdot(n \cdot(q+1))=(m n) \cdot(q+1)$ e assim, pelo Axioma 3, $A=\mathbb{N}$. Logo, $m \cdot(n p)=(m n) \cdot p$, para quaisquer $m, n, p \in \mathbb{N}$.

v) Queremos mostrar que $m n=0 \Rightarrow m=0$ ou $n=0$. Sem perda de generalidade, suponhamos que $n \neq 0$. Logo $n$ é sucessor de um número natural $n_{1}$, ou seja, $n=n_{1}+1$, assim,

$$
0=m n=m \cdot\left(n_{1}+1\right)=m n_{1}+m .
$$

Pela Proposição ?? temos que $m n_{1}=m=0, \operatorname{logo} m=0$.

vi) Queremos mostrar que $n m=m n$. Seja $m$ um número natural qualquer e considere o conjunto

$$
A=\{n \in \mathbb{N}: n m=m n\} .
$$

Primeiro vamos mostrar que $0 \in A$. De fato, temos $m \cdot 0=0$, pela Definição ??. Para provar que $0 \cdot m=0$ consideremos o conjunto

$$
B=\{m \in \mathbb{N}: 0 \cdot m=0\}
$$

Temos que $0 \in B$, pois $0 \cdot 0=0$, pela Definição ??. Considerando um número qualquer $m \in B$, ou seja, $0 \cdot m=0$, devemos mostrar que $0 \cdot(m+1)=0$. Pela Definição ?? temos que $0 \cdot(m+1)=0 \cdot m+0$. Utilizando a hipótese de que $m \in B$, ou seja, $0 \cdot m=0$ obtemos $0 \cdot(m+1)=0$. Logo, pelo Axioma 3, temos que $B=\mathbb{N}$, ou seja, $0 \cdot m=0$. Portanto, $0 \in A$.

Agora suponhamos que $n m=m n$ para algum $n \in A$. Queremos mostrar que $n+1 \in A$, ou seja, $(n+1) \cdot m=m \cdot(n+1)$. Pela Definição ?? e utilizando a hipótese temos,

$$
m \cdot(n+1)=m n+m=n m+m .
$$


Dessa forma temos

$$
(n+1) \cdot m=(n+s(0)) \cdot m=s(n+0) \cdot m=s(n) \cdot m \text {. }
$$

Pela Definição ?? observamos que

$$
\begin{gathered}
n \cdot 2=n \cdot(1+1)=n \cdot 1+n=\underbrace{n+n}_{2 \text { vezes }}, \\
n \cdot 3=n \cdot(2+1)=n \cdot 2+n=\underbrace{n+n+n}_{3 \text { vezes }}, \\
n \cdot 4=n \cdot(3+1)=n \cdot 3+n=\underbrace{n+n+n+n}_{4 \text { vezes }} .
\end{gathered}
$$

Dessa forma temos

$$
s(n) \cdot m=\underbrace{s(n)+s(n)+\ldots+s(n)}_{m \text { vezes }}=\underbrace{(n+1)+(n+1)+\ldots+(n+1)}_{m \text { vezes }} .
$$

Como a adição é associativa e comutativa e usando a Definição ?? temos

$\underbrace{(n+1)+(n+1)+\ldots+(n+1)}_{m \text { vezes }}=\underbrace{n+n+\ldots+n}_{m \text { vezes }}+\underbrace{1+1+\ldots+1}_{m \text { vezes }}=n m+1 \cdot m=n m+m$.

Ou seja,

$$
(n+1) \cdot m=n m+m=m \cdot(n+1) .
$$

Assim, pelo Axioma 3, temos que $A=\mathbb{N}$, ou seja, a comutatividade da multiplicação é válida em $\mathbb{N}$.

\subsection{Relação de ordem em $\mathbb{N}$}

Vamos agora mostrar que $\mathbb{N}$ é um conjunto ordenado. Para isso vamos estabelecer uma relação de ordem em $\mathbb{N}$ utilizando a ideia de relação binária.

Definição 2.4.1. Uma relação binária $R$ em um conjunto não vazio $A$ diz-se uma relação de ordem em $A$ quando satisfazer as condições a seguir, para todos $x, y, z \in A$ :

i) Reflexividade: $x R x$.

ii) Antissimetria: se $x R y$ e $y R x$, então $x=y$.

iii) Transitividade: se $x R y$ e $y R z$, então $x R z$. 
Um conjunto qualquer não vazio munido de uma relação de ordem é chamado de conjunto ordenado.

Definição 2.4.2. Dados $m, n \in \mathbb{N}$, dizemos que $m R n$ se existir $p \in \mathbb{N}$ tal que $n=m+p$.

Definição 2.4.3. Para $m, n \in \mathbb{N}$, se $m R n$ dizemos que $m$ é menor do que ou igual a $n$. Passaremos a escrever o símbolo $\leq$ no lugar de $R$, e desse modo, $m \leq n$ significará $m R n$.

Notação 2.4.1. 1: Se $m \leq n$, porém $m \neq n$, escrevemos $m<n$ e dizemos que $m$ é menor do que $n$.

2: Escrevemos $n \geq m$ como opção para $m \leq n$. Lê-se $n$ é maior do que ou igual a $m$.

3: Escrevemos $n>m$ como opção para $m<n$. Lê-se $n$ é maior do que $m$.

Proposição 2.4.1. Lei da Tricotomia: para quaisquer $m, n \in \mathbb{N}$, temos uma, e somente uma, das relações seguintes ocorrendo:

i) $m<n$.

ii) $m=n$.

iii) $m>n$.

Demonstração. Note que se ocorrer i) e iii), respectivamente, $m<n$ e $m>n$, subentende-se que $m \neq n$, o que contradiz ii), que afirma $m=n$. Logo não pode ocorrer as três relações ao mesmo tempo. Note também que i) e iii) são incompatíveis, pois se $m<n$ então existe $p \in \mathbb{N}^{*}$ tal que $m+p=n$ e se $n<m$ então existe $p_{1} \in \mathbb{N}^{*}$ tal que $n+p_{1}=m$. Logo,

$$
m+p=n \Rightarrow\left(n+p_{1}\right)+p=n \Rightarrow n+\left(p_{1}+p\right)=n \Rightarrow\left(p_{1}+p\right)=0 .
$$

Pela Proposição ?? temos que $p_{1}=p=0$, contradizendo as hipóteses adotadas.

Vamos mostrar agora que, necessariamente, apenas uma das relações ocorre. Seja $m$ um número natural qualquer e considere um conjunto

$$
M=\{x \in \mathbb{N}: x=m, x>m \text { ou } x<m\} .
$$

Temos que $0 \in M$, pois $0=m$ ou $0<m$. Suponhamos que $k \in M$. Queremos mostrar que $k+1 \in M$. Como $k \in M$ podemos ter os seguintes casos:

$1^{o}$ caso: $k=m$. Temos que $k+1=m+1$, ou seja, $k+1>m$. Assim $k+1 \in M$.

$2^{o}$ caso: $k<m$. Temos que existe $p \in \mathbb{N}^{*}$ tal que $k+p=m$, ou seja,

$(k+p)+1=m+1 \Rightarrow k+(p+1)=m+1 \Rightarrow k+(1+p)=m+1 \Rightarrow(k+1)+p=m+1$. 
Como $p \in \mathbb{N}^{*}$, se $p=1$ então $(k+1)=m$. Assim $k+1 \in M$.

$3^{o}$ caso: $k>m$. Temos que existe $p \in \mathbb{N}^{*}$, tal que $k=m+p$, ou seja,

$$
k+1=(m+p)+1 \Rightarrow k+1=m+(p+1) \Rightarrow k+1>m .
$$

Assim, $k+1 \in M$. Pelo Axioma 3 temos que $M=\mathbb{N}$. Assim, concluímos que a Lei da Tricotomia é válida para todos $m, n \in \mathbb{N}$.

Uma relação de ordem que obedece à Lei da Tricotomia é chamada de relação de ordem total. Assim, temos uma relação de ordem total em $\mathbb{N}$.

Teorema 2.4.1. Compatibilidade da relação de ordem com as operações em $\mathbb{N}$ : sejam $a, b$ e $c$ números naturais quaisquer. São verdadeiras as seguintes implicações:

i) $a \leq b \Rightarrow a+c \leq b+c$.

ii) $a \leq b \Rightarrow a c \leq b c$.

Demonstração. i) Se $a \leq b$ então existe $m \in \mathbb{N}$ tal que $a+m=b$. Dessa forma, $(a+m)+c=b+c \Rightarrow a+(m+c)=b+c \Rightarrow a+(c+m)=b+c \Rightarrow(a+c)+m=b+c$.

Assim, $a+c \leq b+c$.

ii) Se $a \leq b$ então existe $m \in \mathbb{N}$ tal que $a+m=b$. Dessa forma,

$$
(a+m) \cdot c=b c \Rightarrow a c+m c=b c .
$$

Assim, $a c \leq b c$.

Teorema 2.4.2. Lei do Cancelamento da Multiplicação: sejam $a, b, c \in \mathbb{N}, \operatorname{com} c \neq 0$. Se $a c=b c$ então $a=b$.

Demonstraçãa. Tomando $a \neq b$ temos as seguintes possibilidades:

i) Se $a>b$ então existe $m_{1} \in \mathbb{N}^{*}$ tal que $a=b+m_{1}$. Dessa forma

$$
a c=\left(b+m_{1}\right) \cdot c \Rightarrow a c=b c+m_{1} c .
$$

Temos $m_{1} \neq 0$ e $c \neq 0$, assim, $a c>b c$.

ii) Se $a<b$ então existe $m_{2} \in \mathbb{N}^{*}$ tal que $a+m_{2}=b$. Dessa forma

$$
\left(a+m_{2}\right) \cdot c=b c \Rightarrow a c+m_{2} c=b c .
$$


Temos $m_{2} \neq 0$ e $c \neq 0$, assim, $a c<b c$.

Com isso temos que $a \neq b(a<b$ ou $a>b)$ implica que $a c \neq b c(a c<b c$ ou $a c>b c$, respectivamente). Assim, $a c=b c$ implica que $a=b$, com $c \neq 0$.

Teorema 2.4.3. Sejam $a, b \in \mathbb{N}$. Temos que $a<b \Leftrightarrow a+1 \leq b$.

Demonstração. Temos que $a<b$ se e somente se existe $c \in \mathbb{N}^{*}$ tal que $a+c=b$. Como $c \neq 0$ então $c=c_{1}+1$, para algum $c_{1} \in \mathbb{N}$. Logo

$$
a+c=b \Leftrightarrow a+\left(c_{1}+1\right)=b \Leftrightarrow a+\left(1+c_{1}\right)=b \Leftrightarrow(a+1)+c_{1}=b .
$$

Assim, $a+1 \leq b$.

Teorema 2.4.4. Princípio da Boa Ordem: todo subconjunto não vazio de números naturais possui um menor elemento.

Demonstração. Seja $S$ um subconjunto não vazio de $\mathbb{N}$ e considere o conjunto

$$
M=\{n \in \mathbb{N}: n \leq x, \forall x \in S\}
$$

ou seja, $M$ é o conjunto de números menores do que ou iguais aos elementos de $S$. Temos que $0 \in M$, pois $0 \leq x$, para todo $x \in S$. Como $S$ é não vazio, tome $s \in S$. Então $s+1 \notin M$, pois $s+1$ não é menor do que ou igual a $s$. $\operatorname{Logo} M \neq \mathbb{N}$. Como $0 \in M$ e $M \neq \mathbb{N}$, então existe um número $m \in M$ tal que $m+1 \notin M$ (caso contrário teríamos $m+1 \in M$ e pelo Axioma 3 teríamos $M=\mathbb{N}$ ). Assim, dizemos que $m$ é o menor elemento de $S$, e denotamos por $m=\min S$. Como $m \in M$, então $m \leq x$, para todo $x \in S$. Suponhamos que $m \notin S$. Então $m<x$, para todo $x \in S$. Pelo Teorema ?? temos que

$$
m<x \Leftrightarrow m+1 \leq x,
$$

para todo $x \in S$, ou seja, $m+1 \in M$, contrariando a escolha de $m$. Logo,

$$
m \in S
$$

Podemos notar, pela demonstração do Teorema ??, que o Princípio de Indução implica no Principio da Boa Ordem. Podemos demonstrar que a recíproca também é verdadeira, demonstrando o Princípio de Indução utilizando o Princípio da Boa Ordem, como será feito a seguir. 
Teorema 2.4.5. Considere $\mathbb{N}$ e $S(n)$ uma proposição que depende de $n \in \mathbb{N}$, tal que

i) $S(0)$ é verdadeira;

ii) Se $m \in \mathbb{N}$ e $S(n)$ é verdadeira, para todo $n \in \mathbb{N}$ tal que $n<m$, então $S(m)$ é verdadeira. Então $S(n)$ é verdadeira para qualquer $n \in \mathbb{N}$.

Demonstração. A demonstração será feita por contradição. Seja $F$ o conjunto dos números naturais a tais que $S(a)$ é falsa. Suponha, por absurdo que $F \neq \emptyset$. Pelo Princípio da Boa Ordem existe um $a_{0} \in F, a_{0}>0$ (já que $S(0)$ é verdadeira) tal que $a_{0} \leq a$, para todo $a \in F$ (isto é, $a_{0}$ é um elemento mínimo de $F$ ). Isto nos diz que $S(n)$ é verdadeira para todo $n \in \mathbb{N}$ tal que $n<a_{0}$ (a não validade desta afirmação comprometeria a minimalidade de $\left.a_{0}\right)$. Pela hipótese ii) temos que $S\left(a_{0}\right)$ é verdadeira, uma contradição. Logo, devemos ter $F=\emptyset$ e $S(n)$ verdadeira para todo $n \in \mathbb{N}$.

Assim, através das demonstrações dos Teoremas ?? e ?? podemos concluir que o Princípio de Indução e o Princípio da Boa Ordem são equivalentes. Dessa forma, concluímos a construção do Conjunto dos Números Naturais. 


\section{Capítulo 3}

\section{Construção dos Números Inteiros}

Nesse capítulo construiremos o conjunto dos números inteiros a partir de $\mathbb{N}$, utilizando a noção de equivalência. As demonstrações serão baseadas no Princípio de Indução, como no capítulo anterior. Definiremos as operações de adição e multiplicação, com suas respectivas propriedades. Continuando o capítulo, estabeleceremos uma relação de ordem nesse conjunto. Também definiremos uma função, chamada de imersão de $\mathbb{N}$ em $\mathbb{Z}$, que mostra que os números inteiros não-negativos tem a mesma estrutura algébrica dos números naturais, além de mostrar que $\mathbb{Z}$ é infinito. Também falaremos do Princípio da Boa Ordem em $\mathbb{Z}$, além de alguns resultados importantes que serão essenciais para o próximo capítulo. Toda a construção será baseada em definições além de teoremas e proposições com suas respectivas demonstrações. Esse capítulo foi baseado em Ferreira ([?]) e em Milies ([?]).

\subsection{Relação de equivalência}

Inicialmente consideraremos o conjunto

$$
\mathbb{N} \times \mathbb{N}=\{(a, b): a, b \in \mathbb{N}\}
$$

A partir desse conjunto será definida uma relação que notaremos por $\sim$.

Definição 3.1.1. Dados dois elementos $(a, b)$ e $(c, d)$ pertencentes a $\mathbb{N} \times \mathbb{N}$, temos que

$$
(a, b) \sim(c, d) \Leftrightarrow a+d=b+c
$$


Proposição 3.1.1. A relação definida acima é uma relação de equivalência.

Demonstração. Para ser uma relação de equivalência temos que verificar três propriedades:

i) Reflexividade: $(a, b) \sim(a, b)$. Temos que

$$
a+b=b+a .
$$

Como a comutatividade é uma propriedade válida para a adição em $\mathbb{N}$ então a reflexividade é válida para a relação.

ii) Simetria: $(a, b) \sim(c, d) \Rightarrow(c, d) \sim(a, b)$. Temos

$$
(a, b) \sim(c, d) \Rightarrow a+d=b+c \Rightarrow d+a=c+b \Rightarrow c+b=d+a \Rightarrow(c, d) \sim(a, b) .
$$

Logo a simetria é válida para a relação.

iii) Transitividade: $(a, b) \sim(c, d)$ e $(c, d) \sim(e, f) \Rightarrow(a, b) \sim(e, f)$. Utilizando as propriedades comutativa, associativa e a lei de cancelamento da adição temos

$$
(a, b) \sim(c, d) \Rightarrow a+d=b+c
$$

$\mathrm{e}$

$$
(c, d) \sim(e, f) \Rightarrow c+f=d+e .
$$

Com isso temos que $(a+d)+(c+f)=(b+c)+(d+e) \Rightarrow a+(d+c)+f=b+(c+d)+e \Rightarrow$ $a+(d+c)+f=b+(d+c)+e \Rightarrow(a+f)+(d+c)=(b+e)+(d+c) \Rightarrow a+f=$ $b+e \Rightarrow(a, b) \sim(e, f)$. Logo a transitividade é válida para a relação.

Consideramos agora o conjunto de todas as classes de equivalência definidas por esta relação. Esse conjunto é chamado de conjunto quociente. Denotaremos por $\overline{(a, b)}$ a classe de equivalência do par ordenado $(a, b)$ pela relação $\sim$, ou seja,

$$
\overline{(a, b)}=\{(x, y) \in \mathbb{N} \times \mathbb{N}:(x, y) \sim(a, b)\}
$$

Definição 3.1.2. O conjunto quociente $\mathbb{N} \times \mathbb{N} / \sim$, constituído por todas as classes de equivalência $\overline{(a, b)}$, será denotado por $\mathbb{Z}$ e chamado de Conjunto dos Números Inteiros.

O símbolo $\mathbb{Z}$ tem origem na palavra alemã zahl, que significa número. 


\subsection{Adição de Números Inteiros}

Nessa seção iremos definir a operação de adição de números inteiros. Mas, antes dessa definição verificaremos se a mesma está bem definida em $\mathbb{Z}$.

Teorema 3.2.1. A adição de números inteiros está bem definida em $\mathbb{Z}$.

Demonstração. Para demonstrar que a adição de números inteiros está bem definida temos que mostrar que a soma não dependerá dos representantes das classes de equivalência citados. Ou seja, se $(a, b) \sim\left(a_{1}, b_{1}\right)$ e $(c, d) \sim\left(c_{1}, d_{1}\right)$, queremos mostrar que

$$
(a+c, b+d) \sim\left(a_{1}+c_{1}, b_{1}+d_{1}\right)
$$

Por hipótese temos que

$$
a+b_{1}=b+a_{1}
$$

e

$$
c+d_{1}=d+c_{1} .
$$

$\operatorname{Logo}\left(a+b_{1}\right)+\left(c+d_{1}\right)=\left(b+a_{1}\right)+\left(d+c_{1}\right) \Rightarrow a+\left(b_{1}+c\right)+d_{1}=b+\left(a_{1}+d\right)+c_{1} \Rightarrow$ $a+\left(c+b_{1}\right)+d_{1}=b+\left(d+a_{1}\right)+c_{1} \Rightarrow(a+c)+\left(b_{1}+d_{1}\right)=(b+d)+\left(a_{1}+c_{1}\right) \Rightarrow$ $(a+c, b+d) \sim\left(a_{1}+c_{1}, b_{1}+d_{1}\right)$. Assim, a adição está bem definida em $\mathbb{Z}$.

Agora que verificamos que a adição está bem definida em $\mathbb{Z}$ iremos definir a operação de adição em $\mathbb{Z}$, utilizando as classes de equivalência como elementos que formam $\mathbb{Z}$.

Definição 3.2.1. Dados $\overline{(a, b)}$ e $\overline{(c, d)}$ elementos em $\mathbb{Z}, \overline{(a, b)}+\overline{(c, d)}=\overline{(a+c, b+d)}$.

Teorema 3.2.2. Sejam $\alpha, \beta$ e $\gamma$ números inteiros quaisquer. São verdadeiras as seguintes afirmações:

i) Propriedade Associativa da Adição: $(\alpha+\beta)+\gamma=\alpha+(\beta+\gamma)$.

ii) Elemento Neutro da Adição: Existe um único elemento denotado por $0 \in \mathbb{Z}$, tal que $\alpha+0=0+\alpha=\alpha$.

iii) Existência de oposto: Para cada inteiro $\beta$ existe um único elemento chamado oposto de $\beta$, ou simétrico de $\beta$, ou ainda inverso aditivo de $\beta$, e denotado por $-\beta$ tal que $\beta+(-\beta)=(-\beta)+\beta=0($ Se $\beta=(c, d)$ então $-\beta=(d, c)$ ).

iv) Propriedade Comutativa da Adição: $\alpha+\beta=\beta+\alpha$.

v) Lei do Cancelamento da Adição: $\alpha+\beta=\gamma+\beta \Rightarrow \alpha=\gamma$. 
Demonstração. Tome $\alpha=\overline{(a, b)}, \beta=\overline{(c, d)}$ e $\gamma=\overline{(e, f)}$.

i) Utilizando a Definição ?? e a associatividade da adição em $\mathbb{N}$ temos que: $(\alpha+\beta)+\gamma=(\overline{(a, b)}+\overline{(c, d)})+\overline{(e, f)}=\overline{(a+c, b+d)}+\overline{(e, f)}=\overline{((a+c)+e,(b+d)+f)}=$ $\overline{(a+(c+e), b+(d+f))}=\overline{(a, b)}+\overline{(c+e, d+f)}=\overline{(a, b)}+(\overline{(c, d)}+\overline{(e, f)})=\alpha+(\beta+\gamma)$.

ii) Esse elemento neutro $0 \in \mathbb{Z}$ escrito na forma de par ordenado é representado por $\overline{(0,0)}$. Pode ser escrito com $\overline{(a, a)}$, pois $\overline{(0,0)}=\overline{(a, a)}$, para todo $a \in \mathbb{N}$. Temos que $\overline{(0,0)}$ é o elemento neutro da adição, pois, para todo $\overline{(a, b)} \in \mathbb{Z}$,

$$
\overline{(0,0)}+\overline{(a, b)}=\overline{(0+a, 0+b)}=\overline{(a, b)}=\overline{(a+0, b+0)}=\overline{(a, b)}+\overline{(0,0)}
$$

A existência foi provada, agora devemos provar a unicidade. Suponhamos que $\overline{\left(a_{1}, b_{1}\right)} \neq \overline{(0,0)}$ seja um outro elemento neutro da adição de $\mathbb{Z}$, logo

$$
\overline{\left(a_{1}, b_{1}\right)}+\overline{(a, b)}=\overline{\left(a_{1}+a, b_{1}+b\right)}=\overline{(a, b)}
$$

e

$$
\overline{(a, b)}+\overline{\left(a_{1}, b_{1}\right)}=\overline{\left(a+a_{1}, b+b_{1}\right)}=\overline{(a, b)} .
$$

Dessa forma temos $a_{1}+a=a=a+a_{1}$ e $b_{1}+b=b=b+b_{1}$. Assim, pela Lei do Cancelamento da Adição em $\mathbb{N}$ temos que

$$
a_{1}+a=a+a_{1}=a+0 \Rightarrow a_{1}=0
$$

e

$$
b_{1}+b=b+b_{1}=b+0 \Rightarrow b_{1}=0
$$

$\operatorname{logo} \overline{(0,0)}$ é o único elemento neutro da adição em $\mathbb{Z}$.

iii) Dado $\beta=\overline{(c, d)} \neq \overline{(0,0)}$ queremos mostrar que existe um $-\beta=\overline{\left(c_{1}, d_{1}\right)}$ tal que:

$$
\beta+(-\beta)=\overline{(c, d)}+\overline{\left(c_{1}, d_{1}\right)}=\overline{\left(c+c_{1}, d+d_{1}\right)}=\overline{(0,0)}
$$

$\mathrm{e}$

$$
(-\beta)+\beta=\overline{\left(c_{1}, d_{1}\right)}+\overline{(c, d)}=\overline{\left(c_{1}+c, d_{1}+d\right)}=\overline{(0,0)} .
$$

Dessa forma temos que

$$
c_{1}+c=c+c_{1}=0=d+d_{1}=d_{1}+d \Rightarrow c+c_{1}=d+d_{1} \Rightarrow \overline{(c, d)}=\overline{\left(d_{1}, c_{1}\right)} .
$$

Assim, $\beta=\overline{(c, d)}$ e $-\beta=\overline{(d, c)}$. 
A existência foi provada, agora devemos provar a unicidade. Suponhamos que $\overline{\left(c_{2}, d_{2}\right)} \neq \overline{\left(c_{1}, d_{1}\right)}$ seja outro simétrico de $\beta$. Temos que

$$
\overline{(c, d)}+\overline{\left(c_{2}, d_{2}\right)}=\overline{\left(c+c_{2}, d+d_{2}\right)}=\overline{(0,0)}
$$

$\mathrm{e}$

$$
\overline{\left(c_{2}, d_{2}\right)}+\overline{(c, d)}=\overline{\left(c_{2}+c, d_{2}+d\right)}=\overline{(0,0)}
$$

Dessa forma temos

$$
c+c_{2}=c_{2}+c=0=d_{2}+d=d+d_{2} \Rightarrow c_{2}+c=d_{2}+d \Rightarrow \overline{\left(c_{2}, d_{2}\right)}=\overline{(d, c)} .
$$

Como $\overline{\left(c_{2}, d_{2}\right)}=\overline{(d, c)}=\overline{\left(c_{1}, d_{1}\right)}$, contradizendo a hipótese, concluímos que o inverso aditivo é único em $\mathbb{Z}$.

iv) Utilizando a Definição ?? e comutatividade em $\mathbb{N}$ temos

$$
\alpha+\beta=\overline{(a, b)}+\overline{(c, d)}=\overline{(a+c, b+d)}=\overline{(c+a, d+b)}=\overline{(c, d)}+\overline{(a, b)}=\beta+\alpha .
$$

v) Utilizando a Definição ?? temos

$$
\alpha+\beta=\overline{(a, b)}+\overline{(c, d)}=\overline{(a+c, b+d)}
$$

e

$$
\gamma+\beta=\overline{(e, f)}+\overline{(c, d)}=\overline{(e+c, f+d)}
$$

Como $\alpha+\beta=\gamma+\beta$ temos que

$$
\overline{(a+c, b+d)}=\overline{(e+c, f+d)} \Rightarrow(a+c)+(f+d)=(b+d)+(e+c) .
$$

Pela Lei do Cancelamento da Adição em $\mathbb{N}$ temos que

$$
(a+c)+(f+d)=(b+d)+(e+c) \Rightarrow a+f=b+e \Rightarrow \overline{(a, b)}=\overline{(e, f)} \Rightarrow \alpha=\gamma
$$

Definição 3.2.2. Dado $\alpha \in \mathbb{Z}$, o único $\beta \in \mathbb{Z}$ tal que $\alpha+\beta=\overline{(0,0)}$ chama-se inverso aditivo de $\alpha$, ou oposto de $\alpha$ ou ainda simétrico de $\alpha$. Como este é único, sua notação será $-\alpha$ (lê-se: menos $\alpha)$.

Devido a existência e unicidade do elemento oposto de um número inteiro, podemos definir uma outra operação em $\mathbb{Z}$, chamada de subtração. 
Definição 3.2.3. A subtração em $\mathbb{Z}$, denotada pelo sinal de (-) é definida assim:

Se $\alpha, \beta \in \mathbb{Z}$, então

$$
\alpha-\beta=\alpha+(-\beta)
$$

Proposição 3.2.1. Para $\alpha, \beta, \gamma \in \mathbb{Z}$, vale:

i) $-(-\alpha)=\alpha$.

ii) $-\alpha+\beta=\beta-\alpha$.

iii) $\alpha-(-\beta)=\alpha+\beta$.

iv) $-\alpha-\beta=-(\alpha+\beta)$.

v) $\alpha-(\beta+\gamma)=\alpha-\beta-\gamma$.

Demonstração. Tome $\alpha=\overline{(a, b)}, \beta=\overline{(c, d)}$ e $\gamma=\overline{(e, f)}$ números inteiros.

i) $-(-\alpha)=-\overline{(b, a)}=\overline{(a, b)}=\alpha$.

ii) $-\alpha+\beta=\overline{(b, a)}+\overline{(c, d)}=(\overline{b+c}, \overline{a+d})=(\overline{c+b}, \overline{d+a})=\overline{(c, d)}+\overline{(b, a)}=\beta-\alpha$.

iii) $\alpha-(-\beta)=\overline{(a, b)}-\overline{(d, c)}=\overline{(a, b)}+\overline{(c, d)}=\alpha+\beta$.

iv) $-\alpha-\beta=\overline{(b, a)}-\overline{(c, d)}=\overline{(b, a)}+\overline{(d, c)}=\overline{(b+d, a+c)}=-(\alpha+\beta)$.

v) $\alpha-(\beta+\gamma)=\overline{(a, b)}-(\overline{(c, d)}+\overline{(e, f)})=\overline{(a, b)}-\overline{(c+e, d+f)}=\overline{(a, b)}+$ $\overline{(d+f, c+e)}=\overline{(a, b)}+\overline{(d, c)}+\overline{(f, e)}=\alpha-\beta-\gamma$.

\subsection{Multiplicação de Números Inteiros}

Nessa seção definiremos a operação de multiplicação de números inteiros. Em seguida verificaremos que a mesma está bem definida em $\mathbb{Z}$. As propriedades da multiplicação também serão demonstradas.

Definição 3.3.1. Dados $\overline{(a, b)}$ e $\overline{(c, d)}$ números inteiros, definimos a multiplicação (ou o produto) $\overline{(a, b)} \cdot \overline{(c, d)}$ como sendo o inteiro $\overline{(a c+b d, a d+b c)}$.

Teorema 3.3.1. A multiplicação de números inteiros está bem definida em $\mathbb{Z}$. Devemos mostrar que se $\overline{(a, b)}=\overline{\left(a_{1}, b_{1}\right)}$ e $\overline{(c, d)}=\overline{\left(c_{1}, d_{1}\right)}$, então $\overline{(a, b)} \cdot \overline{(c, d)}=\overline{\left(a_{1}, b_{1}\right)}$. $\overline{\left(c_{1}, d_{1}\right)}$.

Demonstração. Segue das hipóteses que $a+b_{1}=b+a_{1}$ e $c+d_{1}=d+c_{1}$. Pela Definição ?? temos

$$
\overline{(a, b)} \cdot \overline{(c, d)}=\overline{(a c+b d, a d+b c)}
$$


$\mathrm{e}$

$$
\overline{\left(a_{1}, b_{1}\right)} \cdot \overline{\left(c_{1}, d_{1}\right)}=\overline{\left(a_{1} c_{1}+b_{1} d_{1}, a_{1} d_{1}+b_{1} c_{1}\right)} .
$$

Queremos provar que $\overline{(a c+b d, a d+b c)}=\overline{\left(a_{1} c_{1}+b_{1} d_{1}, a_{1} d_{1}+b_{1} c_{1}\right)}$. Temos que

$$
a+b_{1}=b+a_{1} .
$$

Multiplicando essa equação por $c$ obtemos a equação

$$
\underbrace{a c+b_{1} c=a_{1} c+b c}_{\text {equação } 1} \text {. }
$$

Multiplicando a mesma equação mas agora por $d$ obtemos a equação

$$
a d+b_{1} d=b d+a_{1} d \Rightarrow \underbrace{b d+a_{1} d=a d+b_{1} d}_{\text {equação } 2} .
$$

Somando, membro a membro, as equações 1 e 2 e utilizando as propriedades Associativa e Comutativa da Adição em $\mathbb{N}$ obtemos

$$
\left(a c+b_{1} c\right)+\left(b d+a_{1} d\right)=\left(a_{1} c+b c\right)+\left(a d+b_{1} d\right) \Rightarrow(a c+b d)+\left(a_{1} d+b_{1} c\right)=(a d+b c)+\left(a_{1} c+b_{1} d\right) .
$$

Logo,

$$
\overline{(a c+b d, a d+b c)}=\overline{\left(a_{1} c+b_{1} d, a_{1} d+b_{1} c\right)} .
$$

Devemos mostrar que $\overline{\left(a_{1} c+b_{1} d, a_{1} d+b_{1} c\right)}=\overline{\left(a_{1} c_{1}+b_{1} d_{1}, a_{1} d_{1}+b_{1} c_{1}\right)}$, e por transitividade concluir a demonstração. Temos que,

$$
c+d_{1}=d+c_{1} .
$$

Multiplicando essa equação por $b_{1}$ obtemos a equação

$$
\underbrace{b_{1} c+b_{1} d_{1}=b_{1} c_{1}+b_{1} d}_{\text {equação } 3} .
$$

Multiplicando a mesma equação mas agora por $a_{1}$ obtemos a equação

$$
a_{1} c+a_{1} d_{1}=a_{1} d+a_{1} c_{1} \Rightarrow \underbrace{a_{1} d+a_{1} c_{1}=a_{1} c+a_{1} d_{1}}_{\text {equação } 4} .
$$

Somando, membro a membro, as equações 3 e 4 e utilizando as propriedades Associativa e Comutativa da Adição em $\mathbb{N}$ obtemos 
$\left(b_{1} c+b_{1} d_{1}\right)+\left(a_{1} d+a_{1} c_{1}\right)=\left(b_{1} c_{1}+b_{1} d\right)+\left(a_{1} c+a_{1} d_{1}\right) \Rightarrow\left(a_{1} c_{1}+b_{1} d_{1}\right)+\left(a_{1} d+b_{1} c\right)=$ $\left(a_{1} d_{1}+b_{1} c_{1}\right)+\left(a_{1} c+b_{1} d\right) \Rightarrow \overline{\left(a_{1} c_{1}+b_{1} d_{1}, a_{1} d_{1}+b_{1} c_{1}\right)}=\overline{\left(a_{1} c+b_{1} d, a_{1} d+b_{1} c\right)}$.

Como

$$
\overline{(a c+b d, a d+b c)}=\overline{\left(a_{1} c+b_{1} d, a_{1} d+b_{1} c\right)}=\overline{\left(a_{1} c_{1}+b_{1} d_{1}, a_{1} d_{1}+b_{1} c_{1}\right)},
$$

por transitividade temos que

$$
\overline{(a c+b d, a d+b c)}=\overline{\left(a_{1} c_{1}+b_{1} d_{1}, a_{1} d_{1}+b_{1} c_{1}\right)} .
$$

Assim,

$$
\overline{(a, b)} \cdot \overline{(c, d)}=\overline{\left(a_{1}, b_{1}\right)} \cdot \overline{\left(c_{1}, d_{1}\right)}
$$

Teorema 3.3.2. Sejam $\alpha, \beta$ e $\gamma$ números inteiros quaisquer. São verdadeiras as seguintes afirmações:

i) Propriedade Associativa da Multiplicação: $(\alpha \beta) \cdot \gamma=\alpha \cdot(\beta \gamma)$.

ii) Elemento Neutro da Multiplicação: existe um único elemento, denotado por $1 \in \mathbb{Z}$, tal que $1 \cdot \alpha=\alpha \cdot 1=\alpha$.

iii) Lei do Cancelamento da Multiplicação: para $\alpha \neq 0$, se $\alpha \beta=\alpha \gamma$, então $\beta=\gamma$.

iv) Propriedade Comutativa da Multiplicação: $\alpha \beta=\beta \alpha$.

v) Propriedade Distributiva da Multiplicação em relação à Adição: $\alpha \cdot(\beta+\gamma)=$ $\alpha \beta+\alpha \gamma$.

Demonstração. Considere $\alpha=\overline{(a, b)}, \beta=\overline{(c, d)}$ e $\gamma=\overline{(e, f)}$ números inteiros.

i) Utilizando a Definição ??, as propriedades da Adição e da Multiplicação em $\mathbb{N}$ temos

$$
(\alpha \beta) \cdot \gamma=(\overline{(a, b)} \cdot \overline{(c, d)}) \cdot \overline{(e, f)}=\overline{(a c+b d, a d+b c)} \cdot \overline{(e, f)} .
$$

Dessa forma, $\overline{(a c+b d, a d+b c)} \cdot \overline{(e, f)}=\overline{(e a c+e b d+f a d+f b c, f a c+f b d+e a d+e b c)}=$ $\overline{(a(e c+f d)+b(e d+f c), a(e d+f c)+b(e c+f d))}=\overline{(a, b)} \cdot \overline{(e c+f d, e d+f c)}$. Logo,

$$
\overline{(a, b)} \cdot \overline{(e c+f d, e d+f c)}=\overline{(a, b)} \cdot \overline{(c e+d f, c f+d e)}=\alpha \cdot(\beta \gamma) .
$$

ii) O elemento $1 \in \mathbb{Z}$ é escrito na forma de par ordenado como $\overline{(1,0)}$, ou como $\overline{(a+1, a)}$ já que $\overline{(1,0)}=\overline{(a+1, a)}$, para todo $a \in \mathbb{N}$. Temos que $\overline{(1,0)}$ é o elemento neutro da multiplicação, pois

$$
\overline{(1,0)} \cdot \overline{(a, b)}=\overline{(1 \cdot a+0 \cdot b, 1 \cdot b+0 \cdot a)}=\overline{(a+0, b+0)}=\overline{(a, b)}
$$


$\mathrm{e}$

$$
\overline{(a, b)} \cdot \overline{(1,0)}=\overline{(a \cdot 1+b \cdot 0, a \cdot 0+b \cdot 1)}=\overline{(a+0, b+0)}=\overline{(a, b)} .
$$

A existência foi provada, agora devemos provar a unicidade. Suponhamos que existe um outro elemento neutro multiplicativo $\overline{\left(a_{1}, b_{1}\right)} \neq \overline{(1,0)}$, logo

$$
\overline{(a, b)} \cdot \overline{\left(a_{1}, b_{1}\right)}=\overline{\left(a a_{1}+b b_{1}, a b_{1}+b a_{1}\right)}=(a, b) .
$$

Por outro lado,

$$
\left(a a_{1}+b b_{1}\right)+b=\left(a b_{1}+b a_{1}\right)+a \Rightarrow a a_{1}+b\left(b_{1}+1\right)=a\left(b_{1}+1\right)+b a_{1} .
$$

Dessa forma temos que $a_{1}=b_{1}+1$, ou seja, $\overline{\left(a_{1}, b_{1}\right)}=\overline{(1,0)}$. Assim, o elemento neutro multiplicativo é único.

iii) Tomando $\alpha=\overline{(a, b)} \neq \overline{(0,0)}$, pela Definição ?? e pelas propriedades da Adição e da Multiplicação em $\mathbb{N}$ temos

$\alpha \beta=\alpha \gamma \Rightarrow \overline{(a, b)} \cdot \overline{(c, d)}=\overline{(a . b)} \cdot \overline{(e, f)} \Rightarrow \overline{(a c+b d, a d+b c)}=\overline{(a e+b f, a f+b e)} \Rightarrow$ $(a c+b d)+(a f+b e)=(a d+b c)+(a e+b f) \Rightarrow a(c+f)+b(d+e)=a(d+e)+b(c+f)$. Como $\overline{(a, b)} \neq \overline{(0,0)}$, então

$$
c+f=d+e \Rightarrow \overline{(c, d)}=\overline{(e, f)} \Rightarrow \beta=\gamma .
$$

iv) Pela Definição ?? e pelas propriedades da Adição e Multiplicação em $\mathbb{N}$ temos

$$
\alpha \beta=\overline{(a, b)} \cdot \overline{(c, d)}=\overline{(a c+b d, a d+b c)}=\overline{(c a+d b, c b+d a)}=\overline{(c, d)} \cdot \overline{(a, b)} .
$$

Logo, $\alpha \beta=\beta \alpha$.

v) Temos $\alpha \cdot(\beta+\gamma)=\overline{(a, b)} \cdot(\overline{(c, d)}+\overline{(e, f)})=\overline{(a, b)} \cdot \overline{(c+e, d+f)}$. Pela Definição ?? temos

$$
\overline{(a, b)} \cdot \overline{(c+e, d+f)}=\overline{(a c+a e+b d+b f, a d+a f+b c+b e)} .
$$

Pela propriedade Associativada da Adição em $\mathbb{N}$ temos,

$\overline{(a c+a e+b d+b f, a d+a f+b c+b e)}=\overline{((a c+b d)+(a e+b f),(a d+b c)+(a f+b e))}$.

Como

$\overline{((a c+b d)+(a e+b f),(a d+b c)+(a f+b e))}=\overline{(a c+b d, a d+b c)}+\overline{(a e+b f, a f+b e)}$, concluímos que

$$
\alpha \cdot(\beta+\gamma)=\alpha \beta+\alpha \gamma
$$




\subsection{Relação de ordem em $\mathbb{Z}$}

Definição 3.4.1. Dados $\overline{(a, b)}$ e $\overline{(c, d)}$ números inteiros, escrevemos $\overline{(a, b)} \leq \overline{(c, d)}$ (lê-se $\overline{(a, b)}$ é menor do que ou igual a $\overline{(c, d)}$ ), quando $a+d \leq b+c$.

Proposição 3.4.1. Compatibilidade da relação de ordem com as operações em $\mathbb{Z}$ : sejam $\alpha, \beta$ e $\gamma$ números inteiros quaisquer. São verdadeiras as seguintes afirmações:

i) $\alpha \leq \beta \Rightarrow \alpha+\gamma \leq \beta+\gamma$.

ii) $\alpha \leq \beta$ e $\gamma \geq \overline{(0,0)} \Rightarrow \alpha \gamma \leq \beta \gamma$.

iii) Lei da Tricotomia: Apenas uma, e somente uma das situações seguintes ocorre: $\alpha=\overline{(0,0)}, \alpha<\overline{(0,0)}$ ou $\alpha>\overline{(0,0)}$.

Demonstração. Tome $\alpha=\overline{(a, b)}, \beta=\overline{(c, d)}$ e $\gamma=\overline{(e, f)}$ números inteiros.

i) Se $\alpha \leq \beta$ então $\overline{(a, b)} \leq \overline{(c, d)}$, ou seja, $a+d \leq b+c$. Com isso, existe um $p \in \mathbb{N}^{*}$ tal que $a+d+p=b+c$. Tomando essa última equação, podemos somar $e+f \mathrm{em}$ ambos os membros, ou seja,

$$
a+d+p+(e+f)=b+c+(e+f) \Rightarrow(a+e)+(d+f)+p=(b+f)+(c+e) .
$$

Dessa forma temos

$$
(a+e)+(d+f) \leq(b+f)+(c+e) \Rightarrow \overline{(a+e, b+f)} \leq \overline{(c+e, d+f)},
$$

que implica em

$$
\overline{(a, b)}+\overline{(e, f)} \leq \overline{(c, d)}+\overline{(e, f)} \Rightarrow \alpha+\gamma \leq \beta+\gamma
$$

ii) Se $\alpha \leq \beta$, ou seja, $\overline{(a, b)} \leq \overline{(c, d)}$, então $a+d \leq b+c$. Temos também que se $\gamma \geq \overline{(0,0)}$, ou seja, $\overline{(0,0)} \leq \overline{(e, f)}$, então $f \leq e$. Logo, existem $p, q \in \mathbb{N}$ tais que,

$$
\underbrace{a+d+p=b+c}_{\text {equação } 1}
$$

e

$$
\underbrace{f+q=e}_{\text {equação } 2} .
$$

Multiplicando a equação 1 por $e$ e por $f$, obtemos as equações

$$
a e+d e+p e=b e+c e
$$


$\mathrm{e}$

$$
a f+d f+p f=b f+c f \Rightarrow b f+c f=a f+d f+p f
$$

Somando membro a membro as equações anteriores obtemos

$$
\underbrace{a e+d e+p e+b f+c f=b e+c e+a f+d f+p f}_{\text {equação } 3} .
$$

Multiplicando a equação 2 por $p$ obtemos

$$
p e=p f+p q \Rightarrow p f+p q=p e .
$$

Tomando essa última expressão e somando membro a membro com a equação 3 temos

$$
\begin{aligned}
& a e+d e+p e+b f+c f+p f+p q=a f+d f+p f+b e+c e+p e \Rightarrow \\
& \Rightarrow a e+d e+p f+p q+b f+c f=a f+d f+p f+b e+c e \Rightarrow \\
& \Rightarrow a e+d e+b f+c f+p q=a f+d f+b e+c e \Rightarrow \\
& \Rightarrow a e+d e+b f+c f \leq a f+d f+b e+c e \Rightarrow \\
& \Rightarrow(a e+b f)+(c f+d e) \leq(a f+b e)+(c e+d f) \Rightarrow \\
& \Rightarrow \overline{(a e+b f, a f+b e)} \leq \overline{(c e+d f, c f+d e)} \Rightarrow \overline{(a, b)} \cdot \overline{(e, f)} \leq \overline{(c, d)} \cdot \overline{(e, f)} \Rightarrow \alpha \gamma \leq \beta \gamma .
\end{aligned}
$$

iii) Temos as seguintes situações:

$$
\begin{aligned}
& \overline{(a, b)}=\overline{(0,0)} \Rightarrow a=b, \\
& \overline{(a, b)}<\overline{(0,0)} \Rightarrow a<b
\end{aligned}
$$

e

$$
\overline{(a, b)}>\overline{(0,0)} \Rightarrow a>b
$$

Observando as implicações acima, como a Lei da Tricotomia em $\mathbb{N}$ é verdadeira, e $a, b \in \mathbb{N}$, então a Lei da Tricotomia também é verdadeira em $\mathbb{Z}$.

Teorema 3.4.1. A relação $\leq$ definida anteriormente é uma relação de ordem em $\mathbb{Z}$, quando obedece às seguintes propriedades, para todos $\alpha, \beta$ e $\gamma \in \mathbb{Z}$ :

i) Reflexividade: $\alpha \leq \alpha$.

ii) Antissimetria: se $\alpha \leq \beta$ e $\beta \leq \alpha$ então $\alpha=\beta$.

iii) Transitividade: se $\alpha \leq \beta$ e $\beta \leq \gamma$ então $\alpha \leq \gamma$. 
Demonstração. Tome $\alpha=\overline{(a, b)}, \beta=\overline{(c, d)}$ e $\gamma=\overline{(e, f)}$ números inteiros.

i) Temos $\overline{(a, b)} \leq \overline{(a, b)}$ se e somente se $a+b \leq b+a$. Como $a+b=b+a$, de fato, $a+b \leq b+a$.

ii) Temos que

$$
\alpha \leq \beta \Rightarrow \overline{(a, b)} \leq \overline{(c, d)} \Rightarrow a+d \leq b+c
$$

$\mathrm{e}$

$$
\beta \leq \alpha \Rightarrow \overline{(c, d)} \leq \overline{(a, b)} \Rightarrow c+b \leq d+a \Rightarrow b+c \leq a+d .
$$

Se temos $a+d \leq b+c$ e $b+c \leq a+d$, pela propriedade Antissimétrica da relação de ordem em $\mathbb{N}$, temos $a+d=b+c$. Portanto $\overline{(a, b)}=\overline{(c, d)}$ e assim $\alpha=\beta$.

iii) Temos que

$$
\alpha \leq \beta \Rightarrow \overline{(a, b)} \leq \overline{(c, d)} \Rightarrow a+d \leq b+c
$$

e

$$
\beta \leq \gamma \Rightarrow \overline{(c, d)} \leq \overline{(e, f)} \Rightarrow c+f \leq d+e
$$

Para provar que $\alpha \leq \gamma$ temos que mostrar que $a+f \leq b+e$. Tomando as hipóteses $a+d \leq b+c$ e $c+f \leq d+e$ temos,

$$
(a+d)+(c+f) \leq(b+c)+(d+e) \Rightarrow(a+f)+(d+c) \leq(b+e)+(d+c) .
$$

Utilizando o item i) da Proposição ?? temos que

$$
(a+f) \leq(b+e) \Rightarrow \overline{(a, b)} \leq \overline{(e, f)} \Rightarrow \alpha \leq \gamma
$$

Definição 3.4.2. Dado $\overline{(a, b)} \in \mathbb{Z}$, dizemos que:

i) $\overline{(a, b)}$ é positivo quando $\overline{(a, b)}>\overline{(0,0)}$, ou seja, $a>b$.

ii) $\overline{(a, b)}$ é não negativo quando $\overline{(a, b)} \geq \overline{(0,0)}$, ou seja, $a \geq b$.

iii) $\overline{(a, b)}$ é negativo quando $\overline{(a, b)}<\overline{(0,0)}$, ou seja, $a<b$.

iv) $\overline{(a, b)}$ é não positivo quando $\overline{(a, b)} \leq \overline{(0,0)}$, ou seja, $a \leq b$.

Observe que quando $\overline{(a, b)}>\overline{(0,0)}$, ou seja, $a>b$, existe $m \in \mathbb{N}^{*}$ tal que $a=b+m$, $\operatorname{logo} \overline{(a, b)}=\overline{(m, 0)}$. Analogamente, se $\overline{(a, b)}<\overline{(0,0)}$, ou seja, $a<b$, existe $n \in \mathbb{N}^{*}$ tal que $a+n=b, \operatorname{logo} \overline{(a, b)}=\overline{(0, n)}$. Como a Tricotomia em $\mathbb{Z}$ é válida, temos que

$$
\mathbb{Z}=\left\{\overline{(0, m)}: m \in \mathbb{N}^{*}\right\} \cup\{\overline{(0,0)}\} \cup\left\{\overline{(m, 0)}: m \in \mathbb{N}^{*}\right\}
$$

sendo essas uniões disjuntas. 


\section{Notação 3.4.1.}

$$
\mathbb{Z}_{-}^{*}=\left\{\overline{(0, m)}: m \in \mathbb{N}^{*}\right\}, \mathbb{Z}_{+}^{*}=\left\{\overline{(m, 0)}: m \in \mathbb{N}^{*}\right\}
$$

$\mathrm{e}$

$$
\mathbb{Z}_{-}=\mathbb{Z}_{-}^{*} \cup\{\overline{(0,0)}\}, \mathbb{Z}_{+}=\mathbb{Z}_{+}^{*} \cup\{\overline{(0,0)}\}
$$

Podemos observar também que há um bijeção entre $\mathbb{Z}_{+}$e $\mathbb{N}$ (entre o conjunto dos números inteiros não negativos e o conjunto dos números naturais), ou seja, $\mathbb{Z}_{+}$é uma cópia algébrica de $\mathbb{N}$, como mostra o próximo teorema.

Teorema 3.4.2. Se $f: \mathbb{N} \rightarrow \mathbb{Z}, f(m)=\overline{(m, 0)}$, então $f$ é injetora e valem as seguintes propriedades:

i) $f(m+n)=f(m)+f(n)$;

ii) $f(m n)=f(m) \cdot f(n)$;

iii) Se $m \leq n$ então $f(m) \leq f(n)$.

Demonstração. Para provar a injetividade de $f$ devemos provar que, dados quaisquer $m, n \in \mathbb{N}$, se $m \neq n$ então $f(m) \neq f(n)$. Utilizando a contrapositiva, se $f(m)=f(n)$, então $\overline{(m, 0)}=\overline{(n, 0)}$, e temos $m+0=0+n, \operatorname{logo} m=n$.

i) Queremos mostrar que $f(m+n)=f(m)+f(n)$. Temos

$$
f(m+n)=\overline{(m+n, 0)}=\overline{(m+n, 0+0)}=\overline{(m, 0)}+\overline{(n, 0)}=f(m)+f(n) .
$$

ii) Queremos mostrar que $f(m n)=f(m) \cdot f(n)$. Temos

$$
f(m n)=\overline{(m n, 0)}=\overline{(m n+0 \cdot 0, m \cdot 0+0 \cdot n)}=\overline{(m, 0)} \cdot \overline{(n, 0)}=f(m) \cdot f(n) .
$$

iii) Queremos mostrar que se $m \leq n$ então $f(m) \leq f(n)$. Por hipótese temos $m \leq n$, ou seja, $\overline{(m, n)} \leq \overline{(0,0)}$. Logo

$$
m+0 \leq n+0 \Rightarrow m+0 \leq 0+n \Rightarrow \overline{(m, 0)} \leq \overline{(n, 0)} \Rightarrow f(m) \leq f(n) .
$$

A função $f: \mathbb{N} \rightarrow \mathbb{Z}$ do Teorema ?? chama-se imersão de $\mathbb{N}$ em $\mathbb{Z}$. Nesse Teorema, além de mostrar que $\mathbb{Z}_{+}$tem a mesma estrutura algébrica de $\mathbb{N}$ (preserva as operações e a relação de ordem) mostra também que $\mathbb{Z}$ é infinito.

A partir daqui, os números inteiros serão representados da seguinte forma: 
- Os números do conjunto $\mathbb{Z}_{-}^{*}$, chamados de números negativos, serão representados como $-m=\overline{(0, m)}$.

- Os números do conjunto $\mathbb{Z}_{+}^{*}$, chamados de números positivos, serão representados como $m=+m=\overline{(m, 0)}$.

- O número zero será representado como $0=\overline{(0,0)}$.

Definição 3.4.3. Seja $X$ um subconjunto não vazio de $\mathbb{Z}$. Dizemos que $X$ é limitado inferiormente se existe $\alpha \in \mathbb{Z}$ tal que $\alpha \leq x$, para todo $x \in X$, e $\alpha$ é chamado de cota inferior de $X$. Analogamente, dizemos que $X$ é limitado superiormente se existe $\beta \in \mathbb{Z}$ tal que $x \leq \beta$, para todo $x \in X$, e $\beta$ é chamado de cota superior de $X$.

Teorema 3.4.3. Princípio da Boa Ordem em $\mathbb{Z}$ : seja $X$ um subconjunto não vazio de $\mathbb{Z}$ e limitado inferiormente. Então $X$ possui elemento mínimo.

Demonstração. Seja $\alpha$ uma cota inferior de $X$, isto é, $\alpha \leq x$, para todo $x \in X$. Tomando o conjunto

$$
X_{1}=\{x-\alpha: x \in X\}
$$

temos que $X_{1} \subset \mathbb{N}$ (ou $\mathbb{Z}_{+}$). Pelo Princípio da Boa Ordem em $\mathbb{N}$ o conjunto $X_{1}$ possui elemento mínimo $m_{1}$, ou seja, $m_{1} \in X_{1}$ e $m_{1} \leq y$ para todo $y \in X_{1}$. Como $m_{1} \in X_{1}$ temos que $m_{1}=m-\alpha$, para algum $m \in X$, afirmando que $m=m_{1}+\alpha$ é elemento mínimo de $X$. Devemos verificar que $m \leq x$ para todo $x \in X$. Se $m \leq x$, então $m-\alpha \leq x-\alpha$ para todo $x \in X$. Dessa forma,

$$
m_{1}=m-\alpha \leq x-\alpha=y \Rightarrow m_{1} \leq y,
$$

para todo $y \leq X_{1}$, conforme a definição de $m_{1}$, ou seja, $m$ é elemento mínimo de $X$.

Os próximos resultados serão essenciais para a demonstração que envolve divisores do número 1, um dos assuntos do próximo capítulo.

Corolário 3.4.1. Seja $x \in \mathbb{Z}$ tal que $0<x \leq 1$. Então $x=1$.

Demonstração. Tome o conjunto

$$
A=\{y \in \mathbb{Z}: 0<y \leq 1\}
$$


Tem-se $A \neq \emptyset$, (pois $1 \in A$ ) e $A$ é limitado inferiormente pelo 0. Pelo Princípio da Boa Ordem, $A$ possui elemento mínimo, digamos $m$. Supondo que $m<1$, multiplicando a desigualdade por $m$ temos

$$
0<m<1 \Rightarrow 0<m^{2}<m<1
$$

Com isso temos que $m^{2} \in A$, mas é um absurdo, pois $m$ é o elemento mínimo de $A$. Logo, $m=1$ e $A=\{1\}$.

Corolário 3.4.2. Sejam $n, x \in \mathbb{Z}$ tais que $n<x \leq n+1$. Logo, $x=n+1$.

Demonstração. Tome algum $n \in \mathbb{Z}$ e $A=\{x \in \mathbb{Z}: n<x \leq n+1\}$. Observe que $A$ é não vazio (pois $n+1 \in A$ ) e $A$ é limitado inferiormente pelo $n$. Pelo Princípio da Boa Ordem $A$ possui um elemento mínimo, digamos $m$. Suponhamos que $m<n+1$. Como $m \in A$ temos que

$$
n<m<n+1
$$

Subtraindo $n$ dos membros dessa desigualdade temos

$$
0<m-n<1
$$

Visto que entre 0 e 1 não há números inteiros, como demonstrado no Corolário ??, temos que $m-n=1$, portanto, $m=n+1$.

As considerações sobre módulo feitas a seguir serão utilizadas no capítulo seguinte, ao falarmos sobre o Algoritmo da divisão de Euclides.

Definição 3.4.4. Seja $x \in \mathbb{Z}$. Definimos o valor absoluto de $x$ (ou módulo de $x$ ), denotado por $|x|$, como sendo:

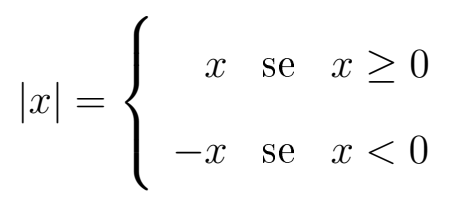

Corolário 3.4.3. Sejam $x, y \in \mathbb{Z}$, temos que $|x y|=|x| \cdot|y|$. 
Demonstração. Para demonstrar que $|x y|=|x| \cdot|y|$ devemos separar nos seguintes casos:

Caso 1: $x, y>0$. Temos que

$$
|x| \cdot|y|=x y=|x y|
$$

Caso 2: $x, y<0$. Temos que

$$
|x y|=(-x)(-y)=x y=|x y|
$$

Caso 3: $x>0$ e $y<0$. Temos que

$$
|x| \cdot|y|=x \cdot(-y)=|x y|
$$

O caso $x<0$ e $y>0$ é análogo.

Assim, temos que $|x y|=|x| \cdot|y|$.

Proposição 3.4.2. Dados $x, y \in \mathbb{Z}$, se $x y=1$ então $x=y=-1$ ou $x=y=+1$.

Demonstração. Note que $x \neq 0$ e $y \neq 0$, pois caso contrário $x y=0$, ou seja, $x y \neq 1$. Seja $x, y \in \mathbb{Z}^{*}$ tais que $x y=1$. Segue que

$$
1=|x y|=|x||y|
$$

Como $|x|>0,|y|>0$ e $|x||y|=1$ temos que $|x| \geq 1$ e $|y| \geq 1$. Multiplicando os membros da desigualdade $|y| \geq 1$ por $|x|$ e utilizando a desigualdade $|x| \geq 1$ temos que

$$
1=|x||y| \geq|x| \geq 1
$$

Assim, $|x|=1$, ou seja, $x=1$ ou $x=-1$. Caso $x=1$, como $x y=1$ temos que $y=x=1$. Caso $x=-1$, como $x y=1$ temos que $y=x=-1$. Logo, $x=y=1$ ou $x=y=-1$.

Assim, terminamos a construção do Conjunto dos Números Inteiros. No capítulo seguinte falaremos sobre divisibilidade e sobre o Algoritmo da divisão de Euclides. 


\section{Capítulo 4}

\section{Divisibilidade}

Este capítulo será composto pela definição de divisão entre dois números inteiros além de algumas propriedades procedentes da mesma. Todo o capítulo será composto de definições, além de teoremas e proposições com suas respectivas demonstrações. $\mathrm{O}$ capítulo será finalizado falando sobre o algoritmo da divisão seguido da demonstração do Algoritmo da divisão de Euclides. Esse capítulo foi baseado em Milies ([?]).

\subsection{Divisão de Números Inteiros}

Definição 4.1.1. Dados $a, b \in \mathbb{Z}$, diz-se que $b$ divide $a$ (ou que $b$ é um divisor de $a$, ou que $a$ é múltiplo de $b$ ) se existe um $c \in \mathbb{Z}$ tal que $b c=a$.

Notação 4.1.1. $b \mid a$ significa que $b$ divide $a$.

$b \nmid a$ significa que $b$ não divide $a$.

Observe que se $b \neq 0$ e $b c=a$ temos que o $c$ é único. Note que, se existisse outro $c_{1} \in \mathbb{Z}$ tal que $b c_{1}=a$, pela Lei do Cancelamento da Multiplicação teríamos

$$
b c=b c_{1} \Rightarrow c=c_{1}
$$

A esse $c$ único chamaremos de quociente de $a$ por $b$, que pode ser indicado como $c=a / b=\frac{a}{b}$. Todavia, se $b=0$, ou seja, $0 \mid a$, então $a=0$. Assim, $0 \cdot c=0$, para todo $c \in \mathbb{Z}, \operatorname{logo} c$ não é único. Por esse motivo admitiremos que o divisor sempre é diferente de zero, mesmo que não seja dito explicitamente. 
Proposição 4.1.1. Dados $b, a \in \mathbb{Z}$, se $b \mid a$ e $a \neq 0$ então $|b| \leq|a|$.

Demonstração. Como $b \mid a$ então existe um $c \in \mathbb{Z}$ tal que $b c=a$. Aplicando módulo na equação anterior temos

$$
|b||c|=|a| .
$$

Como $|c|$ é um inteiro positivo temos que $1 \leq c$. Multiplicando por $|b|$ ambos os membros da desigualdade $1 \leq c$ temos que

$$
|b| \leq|b||c|
$$

Como $|b||c|=|a|$, então $|b| \leq|a|$.

Corolário 4.1.1. Dados $a, b \in \mathbb{Z}$, temos que:

i) Os únicos divisores de 1 são 1 e -1 .

ii) Se $a \mid b$ e $b \mid a$, então $a= \pm b$.

Demonstração. i) Dado um $b \in \mathbb{Z}$ tal que $b \mid 1$, pela Proposição ?? temos que $|b| \leq 1$. Porém, pelo Corolário ?? provamos que se $0<x \leq 1$, então $x=1$, para todo $x \in \mathbb{Z}$. Como $b \neq 0$, então $|b|=1$, portanto $b=+1$ ou $b=-1$.

ii) Se $a \mid b$ então existe um $c \in \mathbb{Z}$ tal que $\underbrace{a c=b}_{\text {equação } 1}$. Se $b \mid a$ então existe um $d \in \mathbb{Z}$ tal que $\underbrace{b d=a}_{\text {equação } 2}$. Substituindo o valor de $b$ da equação 1 na equação 2 temos

$$
(a c) \cdot d=a \Rightarrow a \cdot(c d)=a .
$$

Como $a \neq 0$ (pois é um divisor de b), usando a Lei do Cancelamento da Multiplicação temos

$$
a \cdot(c d)=a \Rightarrow c d=1 .
$$

Dessa forma, $d$ é um divisor de $1, \operatorname{logo}, d= \pm 1$. Assim,

$$
a=b d \Rightarrow a= \pm b
$$

Proposição 4.1.2. Dados $a, b, c, d$ números inteiros quaisquer, assumindo que os divisores são diferentes de zero, temos: 
i) $a \mid a$.

ii) $a \mid b$ e $b|c \Rightarrow a| c$.

iii) $a \mid b$ e $c|d \Leftrightarrow a c| b d$.

iv) $a \mid b$ e $a|c \Rightarrow a|(b+c)$.

v) Se $a \mid b$ então $a \mid m \cdot b$, para todo $m \in \mathbb{Z}$.

vi) Se $a \mid b$ e $a \mid c$ então $a \mid(m b+n c)$, para todos $m, n \in \mathbb{Z}$.

Demonstração. i) Se $a \mid a$ então existe $c \in \mathbb{Z}$ tal que

$$
a c=a \Rightarrow a \cdot 1=a \Rightarrow c=1
$$

ii) Se $a \mid b$ então existe $d \in \mathbb{Z}$ tal que $\underbrace{a d=b}_{\text {equação } 1}$. Se $b \mid c$ então existe um $e \in \mathbb{Z}$ tal que $\underbrace{b e=c}$. Substituindo o valor de $b$ da equação 1 na equação 2 temos equação 2

$$
(a d) \cdot e=c \Rightarrow a \cdot(d e)=c \Rightarrow a \mid c
$$

iii) Se $a \mid b$ então existe $e \in \mathbb{Z}$ tal que $\underbrace{a e=b}_{\text {equação } 1}$. Se $c \mid d$ então existe um $f \in \mathbb{Z}$ tal que $\underbrace{c f=d}$. Multiplicando membro a membro as equações 1 e 2 temos equação 2

$$
(a e) \cdot(c f)=b d \Rightarrow a \cdot(e c) \cdot f=b d \Rightarrow a \cdot(c e) \cdot f=b d \Rightarrow(a c) \cdot(e f)=b d \Rightarrow a c \mid b d .
$$
iv) Se $a \mid b$ então existe $d \in \mathbb{Z}$ tal que $\underbrace{a d=b}_{\text {equação } 1}$. Se $a \mid c$ então existe $e \in \mathbb{Z}$ tal que

$\underbrace{a e=c}$. Somando membro a membro as equações 1 e 2 temos que equação 2

$$
a d+a e=b+c \Rightarrow a \cdot(d+e)=b+c \Rightarrow a \mid(b+c) .
$$

v) Se $a \mid b$ então existe $c \in \mathbb{Z}$ tal que $a c=b$. Multiplicando ambos os membros da equação anterior por $m$ temos

$$
m \cdot(a c)=m b \Rightarrow(m a) \cdot c=m b \Rightarrow(a m) \cdot c=m b \Rightarrow a \cdot(m c)=m b \Rightarrow a \mid(m b) .
$$

vi) Se $a \mid b$ então existe $d \in \mathbb{Z}$ tal que $\underbrace{a d=b}_{\text {equação } 1}$. Se $a \mid c$ então existe um $e \in \mathbb{Z}$ tal que $\underbrace{a e=c}_{\text {equação } 2}$. Multiplicando ambos os membros da equação 1 por $m$ temos

$$
m \cdot(a d)=m b \Rightarrow \underbrace{a \cdot(m d)=m b}_{\text {equação } 3} .
$$


Multiplicando ambos os membros da equação 2 por $n$ temos

$$
n \cdot(a e)=n c \Rightarrow \underbrace{a \cdot(n e)=n c}_{\text {equação } 4} .
$$

Somando membro a membro as equações 3 e 4 temos

$$
a \cdot(m d)+a \cdot(n e)=m b+n c \Rightarrow a \cdot(m d+n e)=m b+n c \Rightarrow a \mid(m b+n c) .
$$

\subsection{Algoritmo da Divisão}

Lema 4.2.1. Dados $a, b \in \mathbb{Z}, a \geq 0$ e $b>0$, existem $q$ e $r$ tais que $a=b q+r$ e $0 \leq r<b$.

Demonstração. Seja o conjunto $S=\{a-(b x): x \in \mathbb{Z}$ e $a-(b x) \geq 0\}$. Se $x=0$ então $a-(b x)=a \geq 0$. Como $a \mid 0$ e $a \in S$, temos que $S \neq \emptyset$. Pelo Princípio da Boa Ordem existe $r=\min S$. Como $r \in S, r=a-(b q) \geq 0$, para algum $q \in \mathbb{Z}$. Temos que mostrar que $r<b$. Se $r \geq b$ teríamos

$$
a-b \cdot(q+1)=a-b \cdot q-b=(a-(b \cdot q))-b=r-b \geq 0 .
$$

Logo, $a-b \cdot(q+1) \in S$. Mas $a-b \cdot(q+1)=r-b<r=\min S$, que é um absurdo. Assim, $r<b$.

\section{Teorema 4.2.1. Algoritmo da Divisão de Euclides}

Dados $a, b \in \mathbb{Z}, b \neq 0$. Então, existem $q, r \in \mathbb{Z}$ únicos tais que $a=b q+r$ e $0 \leq r<|b|$.

Demonstração. Podemos separar em casos:

Caso 1: $b>0$.

Quando $a \geq 0$ o Lema ?? garante a ocorrência do Teorema.

Quando $a<0$ podemos determinar, pelo Lema ??, $q_{1}$ e $r_{1}$ tais que

$$
|a|=b \cdot q_{1}+r_{1}, 0 \leq r_{1}<b .
$$

Se $r_{1}=0$, temos

$$
-|a|=a=b \cdot\left(-q_{1}\right)+0,
$$


$\operatorname{logo}, q=-q_{1}$ e $r=0$ satisfazem as condições do Teorema. Se $r>0$, temos

$$
a=-|a|=b \cdot\left(-q_{1}\right)-r_{1}=b \cdot\left(-q_{1}\right)-b+b-r_{1}=b \cdot\left(-q_{1}-1\right)+\left(b-r_{1}\right) .
$$

Como $0<b-r_{1}<b$ então $q=-q_{1}-1$ e $r=b-r_{1}$ satisfazem as condições do Teorema.

Caso 2: $b<0$.

Qualquer que seja $a$ podemos determinar $q_{1}$ e $r_{1}$ tais que

$$
a=|b| \cdot q_{1}+r_{1}, 0 \leq r_{1}<|b| .
$$

Se $b<0$ então $|b|=-b$. Dessa forma,

$$
a=|b| \cdot q_{1}+r_{1}=(-b) \cdot q_{1}+r_{1}=b \cdot\left(-q_{1}\right)+r_{1} .
$$

Então $q=-q_{1}$ e $r=r_{1}$ satisfazem as condições do Teorema.

Provamos a existência de $q$ e $r$, agora provaremos a unicidade. De fato, $q b+r=$ $a=q_{1} b+r_{1}$. Suponhamos, sem perda de generalidade, que $r_{1} \geq r$. Dessa forma,

$$
\left(q-q_{1}\right) \cdot b=r_{1}-r .
$$

Como $|b|>r_{1}$ temos $r_{1}-r<|b|$. Por outro lado,

$$
\left(q-q_{1}\right) \cdot b=r_{1}-r<|b| \Rightarrow 0 \leq\left|q-q_{1}\right| \cdot|b|<|b| .
$$

Como $|b|>0$ temos que $0 \leq\left|q-q_{1}\right|<1$. Entre 0 e 1 não há números inteiros, como provado no Corolário ??, logo,

$$
\left|q-q_{1}\right|=0 \Rightarrow q=q_{1}
$$

Assim,

$$
q \cdot b+r=q_{1} \cdot b+r_{1} \Rightarrow r=r_{1}
$$

Definição 4.2.1. Os números $q$ e $r$ determinados no Teorema ?? chamam-se, respectivamente, de quociente e resto da divisão de $a$ por $b$.

Com isso, finalizamos toda parte teórica que baseia o tema dessa dissertação. No próximo capítulo serão propostas atividades com o intuito de estimular o estudo do Algoritmo da divisão de Euclides, bem como a sua aplicação em situações-problema. A linguagem matemática formal utilizada nos capítulos anteriores não será utilizada a seguir, já que essas atividades podem ser aplicadas em sala. Dessa forma, a linguagem deve ser simplificada, objetivando o entendimento dos estudantes. 


\section{Capítulo 5}

\section{Atividades Propostas}

Todas as atividades propostas devem ser apresentadas e resolvidas de forma construtiva, incentivando os estudantes a encontrarem as resoluções. De preferência, essas atividades devem ser realizadas em grupo. O professor tem o papel de intermediar, instigar e esclarecer as dúvidas que surgirem ao longo das discussões.

Segundo Zorzan ([?], p. 83), a tendência metodológica conhecida como resolução de problemas desconhece a relação transmissor - receptor, e com isso o ensino da matemática deverá ser conduzido pelo professor de forma diferenciada. Por meio de sua competência técnica, o professor deverá problematizar as questões norteadas pelos conteúdos em sala de aula, além de mediar as resoluções discutidas pelos estudantes. Dessa forma, será proporcionado para o estudante o uso da imaginação e o desenvolvimento da capacidade de ler e interpretar os saberes matemáticos inserido no seu cotidiano.

Portanto, as atividades propostas seguem a tendência resolução de problemas, buscando uma matemática mais criativa e intuitiva.

\subsection{Atividade 1: Matemática e o Calendário}

\subsubsection{História do Calendário}

O Calendário surgiu pela necessidade do homem de marcar o tempo. Conforme Las Casas ([?]), a única maneira de se marcar o tempo seria "tomando por base um evento físico que se repita sempre de uma mesma forma, consequentemente, em um mesmo 
intervalo de tempo."

Segundo Boczko ([?], p.3), é natural se pensar que "a alternância periódica dos intervalos de tempo claro e escuro tenha orientado a vida social mesmo dos mais primitivos seres humanos." Daí surgiu a unidade de medida de tempo chamada de dia, que era medido entre dois aparecimentos do Sol. Dessa forma, o dia era considerado o dia claro (quando o Sol estava presente) com a noite (ausência do Sol).

Além do Sol, a Lua tornou-se notória para medir o tempo. Percebeu-se que a Lua passava por alguns estágios, modificando a sua forma para quem estivesse observando-a de uma determinada parte do planeta. Notou-se quatro estágios, que ficaram conhecidos posteriormente como fases da Lua. Segundo Boczko ([?], p.5), a observação metódica da Lua tornou possível a verificação de que "um ciclo completo de suas fases (chamado de lunação) ocorria num interregno (intervalo de tempo) de cerca de 29 ou 30 dias." Atualmente, sabe-se que o tempo exato para ocorrer um ciclo com as quatro fases da Lua é de 29,530589 dias. Daí surgiu a unidade de medida de tempo chamada mês Lunar, que seriam blocos de 29 ou 30 dias, dependendo do intervalo de tempo para uma lunação.

Segundo Boczko ([?], p.6), a medida que a civilização crescia, "as necessidades sociais tornaram-se mais sofisticadas, e o cômputo de grandes intervalos de tempo passou a ser premente." Notou-se que havia uma alternância de períodos agradáveis com períodos de condições extremas (quente ou frio). Os quatro períodos que se alternavam foram chamados posteriormente de estações do ano. Quando se completava um ciclo com as quatro estações do ano surgiu mais uma unidade de tempo, o Ano Solar.

Composta por 7 dias, a semana foi uma unidade de tempo criada para períodos maiores do que um dia e menores do que um mês. Segundo Boczko ([?], p.7), o motivo de escolher 7 dias para essa medição não está associado a nenhum fenômeno astronômico, apesar de "associá-la a cada uma das 4 fases da Lua, já que cada uma delas tem uma duração aproximada de 7 dias." Segundo Donato ([?], p.18), o número 7 representa para os antigos uma representação gráfica da plenitude, por ser a soma do 3 (considerado o número divino) com o 4 (considerado o número humano). Ainda segundo Donato ([?], p.18), "Quando entenderam que fixar o número de dias do mês pelo curso da Lua, verificaram que, por direta influência divina, o número 28 era perfeitamente divisível por 7 , disso resultando a semana, grupo de 7 dias." Porém, o motivo mais razoável foi o descrito abaixo, por Donato ([?]).

Disposto a encontrar a medida faltante para espaços de tempo superiores ao dia, o homem contou quantos dias a Lua demorava em cada fase. Marcou-se e guiou- 
se pelo número deles na realização de todas as empreitadas que coubesse naquele espaço de tempo. Eram sete os dias de cada fase, aproximadamente. E por isso, a certa altura, esse período recebeu o nome de septimana. Caldeus, babilônicos, judeus e egípcios procederam assim, com maior ou menor aproximação. Mas foi só no ano de 325 , durante o Concílio de Nicéia, que a semana teve legalizada a sua duração de 7 dias. (DONATO, 1978, p.20)

As várias formas de medir o tempo descritas acima fizeram com que surgissem vários tipos de calendários. Segundo Boczko ([?], p.9), podemos definir calendário como sendo "o conjunto de regras e tabelas usadas com a finalidade de agrupar os dias em diversos períodos que possibilitem um fácil cômputo de dias passados ou a passar." Assim, não existe um calendário que seja mais correto do que outros, pois cada um possui uma finalidade, de acordo com a sua concepção.

Conforme Las Casas ([?]), o calendário utilizado hoje no Brasil é conhecido como Calendário Gregoriano, e possui 365,2425 dias. Além disso, existem 97 anos de 366 dias (anos bissextos) em cada período de 400 anos. Os anos nesse calendário possuem 12 meses, alguns com 30 dias (abril, junho, setembro e novembro), alguns com 31 dias (janeiro, março, maio, julho, agosto, outubro e dezembro) e um mês (fevereiro) possui 29 dias nos anos bissextos e 28 dias nos demais anos. Os anos bissextos são determinados pela seguinte regra:

- Todo ano divisível por 4 é bissexto.

- Todo ano divisível por 100 não é bissexto.

- Todo ano divisível por 400 é bissexto.

O item 3 prevalece ao item 2 que por sua vez prevalece ao item 1.

\subsubsection{Atividade relacionando o Calendário Gregoriano com o Algoritmo da divisão de Euclides}

Para relacionar o Algoritmo da divisão de Euclides com o calendário utilizado no Brasil (Calendário Gregoriano), devemos compreender como a atividade pode ser aplicada, facilitando o entendimento dos estudantes e do professor.

A atividade que será proposta foi baseada em outra atividade chamada Desvendando o calendário da Série Matemática na Escola, direcionada ao ensino médio, conforme Paques ([?]). O contexto será análogo ao da atividade original, porém, o nível do raciocínio e o modo de resolução direciona a atividade proposta para estudantes do ensino fundamental (sextos e sétimos anos). Fizemos uma modificação na utilização 
dos números inteiros relacionados com o Algoritmo da divisão de Euclides para uma atividade que utiliza apenas números naturais (a noção de número negativo geralmente é adquirida apenas no $7^{\circ}$ ano do ensino fundamental).

\section{Noções Iniciais sobre o calendário}

Antes de ser realizada a atividade envolvendo o Algoritmo da divisão de Euclides, algumas noções importantes a cerca do contexto a ser utilizado devem ser discutidas com o estudante.

- Unidades de grandeza do tempo: como surgiram e como foram estabelecidas.

- Dia, semana, mês e ano: como surgiram e como são formados.

- Como é dividido o Calendário Gregoriano, utilizado no Brasil: um ano tem 365 dias (exceto o ano bissexto que possui 366 dias), um ano tem 12 meses, cada mês pode ter 30 ou 31 dias com exceção do mês de fevereiro que tem 28 dias (29 dias nos anos bissextos).

- Observação de calendários.

\section{Aplicação da Atividade: Qual é o dia da semana?}

Em seguida devem ser trabalhadas algumas perguntas com os estudantes. As respostas não devem ser dadas de imediato pelo professor. Os estudantes devem ser instigados até que compreendam as perguntas e possam respondê-las de modo satisfatório. Inicialmente, pode ser utilizado um calendário, caso os estudantes estejam com dificuldade de responder as perguntas. Porém, o objetivo é que consigam responder sem esse auxílio.

\section{1 - Que dia é hoje? Que dia da semana é hoje?}

Resposta: Por exemplo, 19.01.2016, uma terça-feira.

2 - Quantos dias têm uma semana? Se voltarmos 7 dias no calendário, que dia da semana será?

Resposta: Uma semana tem 7 dias. Se voltarmos 7 dias no calendário, ou seja, do dia 19.01.2016 para o dia 12.01.2016, estaremos novamente em uma terça-feira.

3 - E se voltarmos 14 dias da semana, que dia da semana será? E 21 dias? E 28 dias? 
Resposta: Os estudantes deverão perceber que, caso voltemos no calendário um número de dias múltiplo de 7 , o dia da semana será o mesmo.

4 - Pensando de modo análogo, qual dia da semana será daqui a 7 dias? E daqui a 14 dias? E daqui a 21 dias? E daqui a 28 dias?

Resposta: Os estudantes deverão perceber que, caso antecipem ou avancem um número múltiplo de 7 no calendário, o dia da semana será o mesmo.

5 - E caso antecipemos 8 dias, que dia da semana será?

Resposta: O objetivo é que eles percebam que, voltando 7 dias seria uma terça-feira, ou seja, para voltar os 8 dias $(7+1)$ basta voltar um dia, logo, seria uma segunda-feira.

\section{6 - E caso antecipemos 16 dias, que dia da semana será?}

Resposta: O objetivo é que eles percebam que, voltando 14 dias seria uma terçafeira, ou seja, para voltar os 16 dias $(14+2)$ basta voltar dois dias, logo, seria um domingo.

7 - Ao invés de anteciparmos, e se avançarmos 8 dias? E se avançarmos 16 dias?

Resposta: De forma análoga às perguntas anteriores, se avançarmos 8 dias seria uma quarta-feira $(7+1)$, e se avançarmos 16 dias seria uma quinta-feira $(14+2)$.

O objetivo principal dessas perguntas é mediar a compreensão pelos estudantes de que eles podem descobrir que dia da semana será uma data escolhida, antes ou depois da data presente. Para isso, deve-se entender que voltar ou avançar um número de dias múltiplo de 7 não altera o dia da semana. Assim, basta antecipar ou avançar o número de dias restantes, após retirar o maior múltiplo de 7 possível do número de dias que está sendo considerado. É importante ressaltar que o material concreto (calendário) não deverá mais ser utilizado, já que isso estimula a abstração da situação pelo estudante, tornando a resolução mais intuitiva.

Qual dia da semana é? - Utilizando o Algoritmo da divisão de Euclides

Após a aplicação e discussão das perguntas anteriores, serão postas as seguintes questões:

8 - E se quisermos voltar 104 dias? Ou voltar 999 dias? Ou ainda, se quisermos avançar 1001 dias? 
Resposta: Os estudantes terão um tempo para discutir, de forma que possam criar algum mecanismo que solucione as questões. Dessa forma, ao socializarem suas ideias vários algoritmos pessoais podem ser criados. A intenção é que tentem relacionar esses casos com os discutidos anteriormente.

Nesse momento, o Algoritmo da divisão de Euclides será relembrado. Através de vários exemplos os estudantes poderão revisar o processo de divisão.

As perguntas anteriores serão retomadas: E se quisermos voltar 104 dias? Ou voltar 999 dias? Ou ainda, se quisermos avançar 1001 dias?

Serão calculadas as divisões de 104 por 7, 999 por 7 e 1001 por 7, e em seguida, os números serão escritos na forma dividendo $=$ divisor $\times$ quociente + resto. Temos,

$$
\begin{array}{r}
104=7 \times 14+6, \\
999=7 \times 142+5, \\
1001=7 \times 143+0 .
\end{array}
$$

No primeiro exemplo, se voltarmos 104 dias no calendário, estaremos voltando 14 semanas e 6 dias, como mostra a expressão $104=7 \times 14+6$. Como vimos nos casos anteriores, voltar $14 \times 7$ dias não altera o dia da semana, logo, precisaremos saber apenas o resto da divisão, que no caso é 6 . Assim, voltando 6 dias, estaremos em uma quarta-feira.

Após essa explicação, deixaremos que os estudantes discutam em grupos quais seriam os dias da semana se voltarmos 999 dias (seria uma quinta-feira) e se avançarmos 1001 dias (seria uma terça-feira). Em seguida, os mesmos apresentarão suas resoluções para o professor e para os outros grupos.

Após essa parte, mais algumas perguntas serão expostas aos estudantes:

9 - Nasci no dia 7 de outubro, qual foi o dia da semana do meu aniversário ano passado?

Resposta: Devemos contar quantos dias voltamos no calendário, a partir de hoje, e utilizar o mesmo raciocínio anterior. Será relembrado o que foi exposto no início da aula:

-1 ano $=365$ dias (anos convencionais) e 1 ano $=366$ dias (anos bissextos).

- Janeiro, Março, Maio, Julho, Agosto, Outubro e Dezembro possuem 31 dias.

- Abril, Junho, Setembro e Novembro possuem 30 dias. 
- Fevereiro possui 28 dias (ano convencional) e 29 dias (ano bissexto).

Como hoje é dia 19.01.2016 (exemplo dado), temos que contar quantos dias antecedem esse dia até o dia 07.10.2015. Contando em partes temos:

- De 07.10.2015 a 31.12.2015 temos: 25 dias $(07.10 .15$ a 31.10.15) + 30 dias (novembro) $+\mathbf{3 1}$ dias $($ dezembro $)=86$ dias .

- De 01.01.2016 a 18.01.2016 temos 18 dias (não incluímos o dia de hoje, pelo exemplo, 19.01.2016).

Logo, temos que voltar um total de $\mathbf{1 0 4}$ dias.

Assim temos $104=\mathbf{7} \times \mathbf{1 4}+\mathbf{6}$, ou seja, temos que voltar $\mathbf{6}$ dias, logo, o dia da semana que caiu o meu aniversário ano passado foi quarta-feira. Os estudantes poderão conferir o dia da semana em algum calendário do ano de 2015 (em seus celulares, por exemplo).

Após essa exposição, serão feitas mais algumas perguntas para que os estudantes discutam e resolvam em grupo:

- Qual será o dia da semana do meu aniversário nesse ano?

- Qual dia da semana será o aniversário de cada integrante do grupo?

- Qual dia da semana foi o Natal do ano passado? E o desse ano?

- Qual dia da semana ocorreu o ataque terrorista às torres gêmeas nos Estados Unidos?

- Qual foi o dia da semana que iniciou o milênio que estamos?

- Qual dia da semana será no dia 01/01/2051?

Após a socialização das ideias e às resoluções dessas atividades, os estudantes poderão fazer uma avaliação acerca de toda a atividade (críticas e sugestões poderão ajudar na avaliação feita pelo professor sobre a atividade, buscando aprimorar a aplicação da mesma).

\subsection{Atividade 2: A História dos Três Marinheiros}

\subsubsection{O Homem que Calculava - Malba Tahan}

Segundo Santana ([?]), apesar de possuir uma biografia (fictícia) e ser o autor de muitas obras relacionadas a matemática e a romances e contos em geral, Malba Tahan é 
um pseudônimo de Júlio César de Melo e Sousa. Nascendo em 6 de maio de 1895, no Rio de Janeiro, o professor de matemática Júlio César ficou conhecido pela sua criatividade em ensinar matemática de forma inusitada. Seu modo de ensinar através de histórias envolvendo Malba Tahan, entre outros personagens, por meio de desafios instigantes revolucionou o modo de ensinar matemática. Como uma forma de reconhecimento pelo modo diferenciado de ensinar e por umas das suas obras mais conhecidas, O Homem que Calculava ([?]), foi fundado o Instituto Malba Tahan, em 2004, na cidade de Queluz. Júlio César morreu no dia 18 de junho de 1974, em Recife.

A atividade que será proposta foi inspirada em uma das histórias contadas no livro O Homem que Calculava, de Tahan ([?], p.147-148).

Um navio que voltava de Serendibe, (nome antigo de Ceilão, atual Sri Lanka) trazendo grande partida de especiarias, foi assaltado por violenta tempestade. A embarcação teria sido destruída pela fúria das ondas se não fosse a bravura e o esforço de três marinheiros que, no meio da tormenta, manejaram as velas com extrema perícia. O comandante, querendo recompensar os denodados marujos, deu-lhes certo número de catis (moeda, unidade de peso). Esse número, superior a duzentos, não chegava a trezentos. As moedas foram colocadas em uma caixa para que no dia seguinte, por ocasião do desembarque, o almoxarife as repartisse entre os três corajosos marinheiros. Aconteceu, porém, que, durante a noite, um dos marinheiros acordou, lembrou-se das moedas e pensou: "Será melhor que eu tire a minha parte. Assim, não terei ocasião de discutir ou brigar com os meus amigos." E, sem nada dizer aos companheiros, foi, pé ante pé, até onde se achava guardado o dinheiro, dividiu-o em três partes iguais, mas notou que a divisão não era exata e que sobrava um catil. "Por causa desta mísera moedinha é capaz de haver amanhã discussão e rixa. O melhor é jogá-la fora." E o marinheiro atirou a moeda ao mar, retirando-se cauteloso. Levava a sua parte e deixava no mesmo lugar o que cabia aos companheiros. Horas depois o segundo marinheiro teve a mesma ideia. Foi à arca que depositara o prêmio coletivo e dividiu-o em três partes iguais. Sobrava uma moeda. Ao marujo, para evitar futuras dúvidas, veio à lembrança atirá-la ao mar. E dali voltou levando consigo a parte a que se julgava com direito. O terceiro marinheiro, ignorando, por completo, a antecipação dos colegas, teve o mesmo alvitre. Levantou-se de madrugada e foi, pé ante pé, à caixa dos catis. Dividiu as moedas que lá encontrou em três partes iguais; a divisão não foi exata. Sobrou um catil. Não querendo complicar o caso, o marujo atirou ao mar a moedinha excedente, retirou a terça parte para si e voltou tranquilo para o seu leito. No dia seguinte, na ocasião do desembarque, o almoxarife do navio encontrou um punhado de catis na caixa. Soube que essas moedas pertenciam aos três marinheiros. Dividiu-as em três partes iguais, dando a cada um dos marujos um dessas partes. Ainda dessa vez a divisão não foi exata. Sobrava uma moeda, que o almoxarife guardou como paga do seu trabalho e de sua habilidade. É claro que nenhum dos marinheiros reclamou, pois cada um deles estava convencido de que já havia retirado da caixa a parte que lhe cabia do dinheiro. Pergunta-se, 
afinal: Quantas eram as moedas? Quanto recebeu cada um dos marujos?

Utilizando a ideia de divisões não exatas exposta nessa história, podem ser aplicadas atividades similares, a partir do $6^{\circ}$ ano do ensino fundamental (apesar da noção do algoritmo da divisão de Euclides ser apresentada pela primeira vez no $4^{\circ}$ ano, temos que ter a cautela de aplicar essa atividade após a verificação de que os estudantes realmente compreenderam esse conceito).

\subsubsection{Atividade relacionando a história dos Três Marinheiros com o Algoritmo da divisão de Euclides}

A resolução mais conhecida da história dos Três Marinheiros geralmente é aplicada para estudantes do primeiro ano do ensino médio, já que envolve resolução de sistema de equações e manipulações mais sofisticadas. Dessa forma, fizemos modificações para que a atividade pudesse ser aplicada nos anos finais do ensino fundamental, aos estudantes que já conhecem o Algoritmo da divisão de Euclides. Assim, segue a atividade proposta com essas modificações.

\section{Atividades Iniciais}

Inicialmente seria feita a leitura da história, de forma que os estudantes pudessem elaborar hipóteses iniciais de resolução do problema, entre outras dicussões.

Em seguida, antes de propor efetivamente a resolução em questão, a turma deve ser dividida em grupos de no máximo quatro estudantes, para facilitar a discussão, e devem ser trabalhadas as perguntas a seguir.

\section{1 - Quais são os números múltilplos de 3 que estão entre 50 e 100?}

Resolução: Nessa atividade provavelmente a maioria dos estudantes realizarão a divisão de todos os números de 51 a 99 para verificar quais são os múltiplos de 3 . Caso algum grupo não tenha tido a ideia proposta a seguir, o professor deverá instigar até que os estudantes compreendam.

Para descobrir os múltiplos de 3 entre 50 e 100 basta dividir os primeiros números por 3:

$$
\begin{aligned}
& 51=3 \times 17+0 \\
& 52=3 \times 17+1
\end{aligned}
$$




$$
\begin{aligned}
& 53=3 \times 17+2 \\
& 54=3 \times 18+0 \\
& 55=3 \times 18+1 \\
& 56=3 \times 18+2
\end{aligned}
$$

Podemos observar que para determinar os múltiplos de 3 basta descobrir o primeiro que seja múltiplo de 3 , e ir contando de 3 em 3 para encontrar os outros, ou seja, não precisa realizar todas as divisões.

Assim, os múltiplos de 3 entre 50 e 100 são: 51, 54, 57, 60, 63, 66, 69, 72, 75, 78, 81, 84, 87, 90, 93, 96, 99 .

\section{2 - Quais são os números entre 50 e 100 que deixam resto 1 na divisão} por 4 ?

Resolução: De forma análoga a resolução anterior, a maioria dos estudantes devem descobrir esses números realizando a divisão de 51 até 99 por 4 . Caso algum grupo não tenha relacionado o modo de resolução sem ter que dividir todos os números por 4 o professor deverá instigá-los até resolvam.

Para descobrir os números que divididos por 4 deixam resto 1 entre 50 e 100 basta dividir os primeiros números:

$$
\begin{aligned}
& 51=4 \times 12+3 \\
& 52=4 \times 13+0 \\
& 53=4 \times 13+1 \\
& 54=4 \times 13+2 \\
& 55=4 \times 13+3 \\
& 56=4 \times 14+0 \\
& 57=4 \times 14+1 \\
& 58=4 \times 14+2
\end{aligned}
$$


Podemos observar que para determinar esses números basta encontrar o primeiro número que dividido por 4 deixa resto 1 e ir contando de $4 \mathrm{em} \mathrm{4}$, de forma análoga aos múltiplos de 3 na questão anterior.

Assim, os números procurados são: 53, 57, 61, 65, 69, 73, 77, 81, 85, 89, 93, 97.

Para discutir bem esse raciocínio, antes de resolver o problema dos Três Marinheiros seria interessante colocar mais algumas perguntas cujos modos de resolução sejam semelhantes às anteriores, como essas que elaboramos:

3 - Quais são os números entre 100 e 200 que divididos por 5 deixam resto 3 ?

4 - Quais são os números entre 100 e 200 que divididos por 3 deixam resto 2 e são pares?

5 - Tenho um certa quantidade de moedas, que passa de 300 mas não chega a 350. Dividi essas moedas entre minhas duas irmãs e eu, mas ao dividir percebi que restou 2 moedas. Quais são as quantidades possiveis para o número de moedas?

6 -Um colar é feito da seguinte forma: 4 miçangas serão colocadas no fio, depois é dado um nó, depois coloca-se mais 4 miçangas e em seguida mais um outro nó, até que sejam colocadas todas as miçangas disponíveis em uma caixa. Ao começar a fazer o colar, sem querer, deixei que 2 miçangas caíssem no chão, e não consegui encontrá-las. Depois de terminar de colocar todas as miçangas, o colar terminou com um nó e mais 4 miçangas. Sabendo que a quantidade de miçangas que tinha na caixa inicialmente era mais do que 30, mas não chegava a 38, quantas miçangas tinham na caixa?

7 - Em um parque de diversão havia um brinquedo o qual podia-se trocar uma ficha por um certa quantidade de bolinhas, para que fossem jogadas no alvo, com o objetivo de ganhar um prêmio. Troquei duas fichas e ao receber a quantidade de bolinhas correspondentes dividi entre meus quatro irmãos e eu. Depois de dividir igualmente, sobrou 4 bolinhas, que foram entregues para os meus quatro irmãos, por serem mais habilidosos. Qual quantidade de bolinhas equivalem a uma ficha sabendo que recebi uma quantidade entre 40 a 50 e que era uma quantidade par?

Os grupos devem resolver as questões que serão discutidas posteriormente com toda a turma.

\section{Resolução do Problema do Três Marinheiros - adaptado}


Após a aplicação e discussão dessas questões será posto o Problema dos Três Marinheiros. Porém, fizemos a seguinte adaptação: ao invés da quantidade de moedas ser entre 200 e 300, será entre 50 e 90. Essa adaptação facilitará a compreensão da resolução proposta, visto que pode ser aplicada para estudantes dos sextos e sétimos anos do ensino fundamental. O problema original pode ser proposto para turmas mais avançadas, ou logo após a aplicação do problema adaptado. Os grupos terão um tempo para pensar a respeito e tentar encontrar uma solução para o mesmo.

Os estudantes irão sugerir formas de como encontrar a resposta. Caso o problema não tenha sido resolvido, o professor irá mediar por meio de algumas reflexões que elaboramos, com a intenção de que a resolução se torne intuitiva. As reflexões estão listadas a seguir.

Reflexão 1: Inicialmente a arca tinha uma quantidade de moedas. Quais são os valores possíveis de moedas contidos na arca inicialmente?

Resolução: Basta que os estudantes percebam que na história fala que a quantidade de moedas passavam de 50 mais não chegava a 90. Assim, na arca poderia ter 51,52 , $53, \ldots, 88$ ou 89 moedas.

Reflexão 2: O primeiro marinheiro acordou durante a noite para pegar a sua parte da recompensa. Ao dividir a quantidade de moedas em três percebeu que sobrou uma moeda, então ele jogou ela no mar. Quais são as possibilidades para a quantidade de moedas na arca sabendo dessa informação?

Resolução: Os estudantes devem perceber que a quantidade de moedas na arca quando divididos por 3 deixou resto 1 , ou seja, seguindo o raciocínio já trabalhado temos:

$$
\begin{aligned}
& 51=3 \times 17+0 \\
& 52=3 \times 17+1 \\
& 53=3 \times 17+2 \\
& 54=3 \times 18+0 \\
& 55=3 \times 18+1
\end{aligned}
$$


Assim, as quantidades possíveis que o primeiro marinheiro encontrou na arca foram: $52,55,58,61,64,67,70,73,76,79,82,85,88$ (ou seja, de 52 a 88 pulando de 3 em $3)$.

Reflexão 3: O primeiro marinheiro jogou a moeda que restou ao mar, pegou a terça parte da quantidade que tinha, deixando dois terços na arca e voltou a dormir. Quais são as quantidades possíveis de moedas que ficaram na arca depois dessa retirada?

Resolução: Os estudantes devem perceber que o modo dividendo $=$ divisor $\times$ quociente + resto facilita a determinação dessas possíveis quantidades:

$$
\begin{gathered}
52=3 \times \mathbf{1 7}+1 \\
55=3 \times \mathbf{1 8}+1 \\
58=3 \times \mathbf{1 9}+1 \\
61=3 \times \mathbf{2 0}+1 \\
\cdots \\
85=3 \times \mathbf{2 8}+1 \\
88=3 \times \mathbf{2 9}+1 .
\end{gathered}
$$

Como o primeiro marinheiro pegou um terço, ele pode ter pego 17, 18, 19, ..., 28 ou 29 moedas, e pode ter deixado o dobro desse valor (que equivale a dois terços) na arca, ou seja, pode ter deixado $34,36,38,40,42,44,46,48,50,52,54,56$ ou 58 moedas na arca (ou seja, de 34 a 58 pulando de 2 em 2).

Reflexão 4: Em seguida o segundo marinheiro foi até a arca e com as moedas que estavam lá ele dividiu em três partes, jogando fora a moeda que restou. Dos valores possíveis determinados anteriormente, quais são as quantidades possíveis que o segundo marinheiro encontrou na arca?

Resolução: Os estudantes devem perceber que os valores possíveis são aqueles que divididos por 3 deixam resto 1 , logo:

$$
\begin{aligned}
& 34=3 \times 11+1 \\
& 36=3 \times 12+0 \\
& 38=3 \times 12+2
\end{aligned}
$$




$$
\begin{aligned}
& 40=3 \times 13+1 \\
& 42=3 \times 14+0 \\
& 44=3 \times 14+2 \\
& 46=3 \times 15+1 \\
& 48=3 \times 16+0 \\
& 50=3 \times 16+2 \\
& 52=3 \times 17+1 \\
& 54=3 \times 18+0 \\
& 56=3 \times 18+2 \\
& 58=3 \times 19+1 .
\end{aligned}
$$

Os valores possíveis agora são: 34, 40, 46, 52 e 58 (note que os são os números de 34 a 58 , contando de 6 em 6$)$.

Reflexão 5: O segundo marinheiro, após jogar a moeda que restou ao mar, também pegou a terça parte da quantidade que tinha, deixando dois terços na arca e voltou a dormir. Quais são as quantidades possíveis de moedas que ficaram na arca depois dessa outra retirada?

Resolução: Como feito anteriormente, basta escrever os números no modo dividendo $=$ divisor $\times$ quociente + resto:

$$
\begin{aligned}
& 34=3 \times \mathbf{1 1}+1 \\
& 40=3 \times \mathbf{1 3}+1 \\
& 46=3 \times \mathbf{1 5}+1 \\
& 52=3 \times \mathbf{1 7}+1 \\
& 58=3 \times \mathbf{1 9}+1 .
\end{aligned}
$$

Como o segundo marinheiro pegou um terço, ele pode ter pego 11, 13, 15, 17 ou 19 moedas, e pode ter deixado o dobro desse valor (que equivale a dois terços) na arca, ou seja, pode ter deixado 22, 26, 30, 34 ou 38 moedas (ou seja, de 22 até 38 pulando de 4 em 4). 
Reflexão 6: Mais tarde o terceiro marinheiro também foi até a arca e com as moedas que estavam lá naquele momento ele dividiu em três partes, jogando fora a moeda que restou. Dos valores possíveis determinados na reflexão anterior, quais são as quantidades possíveis que o terceiro marinheiro encontrou?

Resolução: Os estudantes devem perceber que os valores possíveis são aqueles que divididos por 3 deixam resto 1 , logo:

$$
\begin{gathered}
22=3 \times 7+1 \\
26=3 \times 8+2 \\
30=3 \times 10+0 \\
34=3 \times 11+1 \\
38=3 \times 12+2 .
\end{gathered}
$$

As quantidades possíveis serão: 22 ou 34 moedas.

Reflexão 7: O terceiro marinheiro também jogou a moeda que restou no mar e como os outros marinheiros pegou a terça parte da quantidade que tinha, deixando dois terços na arca e voltou a dormir. Quais são as quantidades possíveis de moedas que ficaram na arca depois dessa última retirada?

Resolução: Do mesmo modo, escrevendo os números no modo dividendo = divisor $\times$ quociente + resto temos:

$$
\begin{gathered}
22=3 \times \mathbf{7}+1 \\
34=3 \times \mathbf{1 1}+1 .
\end{gathered}
$$

Como os outros marinheiros, o terceiro pegou um terço, no caso ele pode ter pego 7 ou 11 moedas, e deixou na arca o dobro (que equivale a dois terços), ou seja, 14 ou 22 moedas.

Reflexão 8: No dia seguinte o almoxarife fez a divisão entre os três marinheiros das moedas que estavam na arca, e a moeda que restou ficou com ele para pagar os seus serviços. Dos valores possíveis encontrados anteriormente, qual(is) seria(m) a(s) quantidade(s) possível(is) de moedas encontrada(s) pelo almoxarife?

Resolução: Os estudantes devem perceber que os valores possíveis são aqueles que divididos por 3 deixam resto 1 , logo: 


$$
\begin{aligned}
& 14=3 \times 4+2 \\
& 22=3 \times 7+1 .
\end{aligned}
$$

Desse modo, a única quantidade possível encontrada pelo almoxarife foi de 22 moedas.

Reflexão 9: Utilizando as informações obtidas nas reflexões anteriores, quantas moedas tinham na arca inicialmente?

Resolução: Os estudantes apresentarão as suas ideias de como realizar esse cálculo. Caso a ideia a seguir não tenha sido sugerida por algum grupo a mesma será exposta pelo professor, de forma que os estudantes respondam a medida que as questões estão sendo colocadas:

- No dia seguinte, quando o almoxarife dividiu as moedas entre os marinheiros ele encontrou 22 moedas. Lembrando que o almoxarife ficou com uma moeda, quantas moedas cada marinheiros ganhou?

Cada marinheiro recebeu 7 moedas $(22=3 \times 7+1)$.

- Sabendo que o terceiro marinheiro tinha deixado dois terços na arca, tinha pego um terço e tinha jogado uma moeda ao mar, quantas moedas o terceiro marinheiro encontrou na arca antes da retirada?

Como 22 moedas são dois terços, então um terço são 11 moedas, ou seja, o terceiro marinheiro encontrou 34 moedas $(34=3 \times 11+1)$.

- Sabendo que a quantidade de moedas deixadas pelo segundo marinheiro foi a quantidade encontrada pelo terceiro marinheiro e que o segundo marinheiro também tinha deixado dois terços na arca, tinha pego um terço e tinha jogado uma moeda ao mar, quantas moedas o segundo marinheiro encontrou na arca antes da retirada?

Como 34 moedas são dois terços, então um terço são 17 moedas, ou seja, o segundo marinheiro encontrou 52 moedas $(52=3 \times 17+1)$.

- Sabendo que a quantidade de moedas deixadas pelo primeiro marinheiro foi encontrada pelo segundo marinheiro e que o primeiro marinheiro fez o mesmo processo dos outros dois, quantas moedas o primeiro marinheiro encontrou na arca antes da retirada? 
Como 52 moedas são dois terços, então um terço são 26 moedas, ou seja, o primeiro marinheiro encontrou 79 moedas $(79=3 \times 26+1)$.

Assim, a quantidade de moedas que havia na arca inicialmente era de 79 MoEDAs.

Reflexão 10: Das 79 moedas colocadas inicialmente na arca, qual foi o destino delas?

Resolução: Basta somar as moedas que cada um dos marinheiros retirou da arca com as moedas que eles receberam do almoxarife, além das outras quatro moedas (três jogadas ao mar e uma que foi o pagamento do almoxarife):

- Primeiro marinheiro: $26+7=33$ moedas.

- Segundo marinheiro: $17+7=24$ moedas.

- Terceiro marinheiro: $11+7=18$ moedas.

- Jogadas ao mar: 3 moedas.

- Almoxarife: 1 moeda.

$$
33+24+18+3+1=79 .
$$

Algumas perguntas adicionais podem ser discutidas com os estudantes, como por exemplo:

- Supondo que nenhum dos marinheiros tivessem retirado moedas antes de serem repartidas pelo almoxarife, quantas moedas cada um receberia?

- Nessa situação, qual dos marinheiros receberiam mais moedas do que na situação inicial? E menos moedas? Algum marinheiro receberia a mesma quantidade de moedas?

- Ainda na suposta situação, quantas moedas receberia o almoxarife? Alguma moeda seria jogada ao mar?

\section{Resolução do Problema dos Três Marinheiros - original}

Da mesma forma que a resolução do Problema dos Três Marinheiros adaptado foi direcionada anteriormente, a seguir, o problema original será resolvido. De modo 
similar, os estudantes irão sugerir formas de como encontrar a resposta, e após as intervenções do professor, caso o problema não tenha sido resolvido, a resolução do problema será direcionada pelas mesmas reflexões anteriores.

Reflexão 1: Inicialmente a arca tinha uma quantidade de moedas. Quais são os valores possíveis de moedas contidos na arca inicialmente?

Resolução: Basta que os estudantes percebam que na história fala que a quantidade de moedas passavam de 200 mais não chegava a 300. Assim, na arca poderia ter 201, 202, 203, ..., 298 ou 299 moedas.

Reflexão 2: O primeiro marinheiro acordou durante a noite para pegar a sua parte da recompensa. Ao dividir a quantidade de moedas em três percebeu que sobrou uma moeda, então ele jogou ela no mar. Quais são as possibilidades para a quantidade de moedas na arca sabendo dessa informação?

Resolução: Os estudantes devem perceber que a quantidade de moedas na arca quando divididos por 3 deixou resto 1 , ou seja, seguindo o raciocínio já trabalhado temos:

$$
\begin{gathered}
201=3 \times 67+0 \\
202=3 \times 67+1 \\
203=3 \times 67+2 \\
204=3 \times 68+0 \\
205=3 \times 68+1 \\
\quad \ldots \\
298=3 \times 99+1 \\
299=3 \times 99+2 .
\end{gathered}
$$

Assim, as quantidades possíveis que o primeiro marinheiro encontrou na arca foram: 202, 205, 208, 211, 214, ..., 295, 298 (ou seja, de 202 a 298 pulando de 3 em 3).

Reflexão 3: O primeiro marinheiro jogou a moeda que restou ao mar, pegou a terça parte da quantidade que tinha, deixando dois terços na arca e voltou a dormir. Quais são as quantidades possíveis de moedas que ficaram na arca depois dessa retirada? 
Resolução: Os estudantes devem perceber que o modo dividendo $=$ divisor $\times$ quociente + resto facilita a determinação dessas possíveis quantidades:

$$
\begin{gathered}
202=3 \times \mathbf{6 7}+1 \\
205=3 \times \mathbf{6 8}+1 \\
208=3 \times \mathbf{6 9}+1 \\
221=3 \times \mathbf{7 0}+1 \\
\cdots \\
295=3 \times \mathbf{9 8}+1 \\
298=3 \times \mathbf{9 9}+1 .
\end{gathered}
$$

Como o primeiro marinheiro pegou um terço, ele pode ter pego $67,68,69, \ldots, 98$ ou 99 moedas, e pode ter deixado o dobro desse valor (que equivale a dois terços) na arca, ou seja, pode ter deixado 134, 136, 138, .., 196 ou 198 moedas na arca (ou seja, de 134 a 198 pulando de 2 em 2).

Reflexão 4: Em seguida o segundo marinheiro foi até a arca e com as moedas que estavam lá ele dividiu em três partes, jogando fora a moeda que restou. Dos valores possíveis determinados anteriormente, quais são as quantidades possíveis que o segundo marinheiro encontrou na arca?

Resolução: Os estudantes devem perceber que os valores possíveis são aqueles que divididos por 3 deixam resto 1, logo:

$$
\begin{array}{r}
134=3 \times 44+2 \\
136=3 \times 45+1 \\
138=3 \times 46+0 \\
140=3 \times 46+2 \\
142=3 \times 47+1 \\
\quad \cdots \\
194=3 \times 64+2 \\
196=3 \times 65+1
\end{array}
$$




$$
198=3 \times 66+0 .
$$

Os valores possíveis agora são: 136, 142, 148, ..., 190 e 196 (note que os são os números de 136 a 196, contando de 6 em 6).

Reflexão 5: O segundo marinheiro, após jogar a moeda que restou ao mar, também pegou a terça parte da quantidade que tinha, deixando dois terços na arca e voltou a dormir. Quais são as quantidades possíveis de moedas que ficaram na arca depois dessa outra retirada?

Resolução: Como feito anteriormente, basta escrever os números no modo dividendo $=$ divisor $\times$ quociente + resto:

$$
\begin{aligned}
136= & 3 \times \mathbf{4 5}+1 \\
142= & 3 \times \mathbf{4 7}+1 \\
148= & 3 \times \mathbf{4 9}+1 \\
154= & 3 \times \mathbf{5 1}+1 \\
& \cdots \\
190= & 3 \times \mathbf{6 3}+1 \\
196= & 3 \times \mathbf{6 5}+1 .
\end{aligned}
$$

Como o segundo marinheiro pegou um terço, ele pode ter pego 45, 47, 49, 51, .., 63 ou 65 moedas, e pode ter deixado o dobro desse valor (que equivale a dois terços) na arca, ou seja, pode ter deixado 90, 94, 98, 102, ..., 126 ou 130 moedas (ou seja, de 90 até 130 pulando de 4 em 4).

Reflexão 6: Mais tarde o terceiro marinheiro também foi até a arca e com as moedas que estavam lá naquele momento ele dividiu em três partes, jogando fora a moeda que restou. Dos valores possíveis determinados na reflexão anterior, quais são as quantidades possíveis que o terceiro marinheiro encontrou?

Resolução: Os estudantes devem perceber que os valores possíveis são aqueles que divididos por 3 deixam resto 1 , logo:

$$
\begin{aligned}
& 90=3 \times 30+0 \\
& 94=3 \times 31+1
\end{aligned}
$$




$$
\begin{gathered}
98=3 \times 96+2 \\
102=3 \times 34+0 \\
106=3 \times 35+1 \\
\quad \ldots \\
118=3 \times 39+1 \\
122=3 \times 40+2 \\
126=3 \times 42+0 \\
130=3 \times 43+1 .
\end{gathered}
$$

As quantidades possíveis serão: 94, 106, 118, ou 130 moedas (ou seja, de 94 a 130 pulando de 12 em 12).

Reflexão 7: O terceiro marinheiro também jogou a moeda que restou no mar e como os outros marinheiros pegou a terça parte da quantidade que tinha, deixando dois terços na arca e voltou a dormir. Quais são as quantidades possíveis de moedas que ficaram na arca depois dessa última retirada?

Resolução: Do mesmo modo, escrevendo os números no modo dividendo = divisor $\times$ quociente + resto temos:

$$
\begin{array}{r}
94=3 \times \mathbf{3 1}+1 \\
106=3 \times \mathbf{3 5}+1 \\
118=3 \times \mathbf{3 9}+1 \\
130=3 \times \mathbf{4 3}+1 .
\end{array}
$$

Como os outros marinheiros, o terceiro pegou um terço, no caso ele pode ter pego 31, 35, 39 ou 43 moedas, e deixou na arca o dobro (que equivale a dois terços), ou seja, $62,70,78$ ou 86 moedas.

Reflexão 8: No dia seguinte o almoxarife fez a divisão entre os três marinheiros das moedas que estavam na arca, e a moeda que restou ficou com ele para pagar os seus serviços. Dos valores possíveis encontrados anteriormente, qual(is) seria(m) a(s) quantidade(s) possível(is) de moedas encontradas pelo almoxarife?

Resolução: Os estudantes devem perceber que os valores possíveis são aqueles que divididos por 3 deixam resto 1, logo: 


$$
\begin{aligned}
& 62=3 \times 20+2 \\
& 70=3 \times 23+1 \\
& 78=3 \times 26+0 \\
& 86=3 \times 28+2 .
\end{aligned}
$$

Desse modo, a única quantidade possível encontrada pelo almoxarife foi de 70 moedas.

Reflexão 9: Utilizando as informações obtidas nas reflexões anteriores, quantas moedas tinham na arca inicialmente?

Resolução: Os estudantes apresentarão as suas ideias de como realizar esse cálculo. Caso a ideia a seguir não tenha sido sugerida por algum grupo a mesma será exposta pelo professor, de forma que os estudantes respondam a medida que as questões estão sendo colocadas:

- No dia seguinte, quando o almoxarife dividiu as moedas entre os marinheiros ele encontrou 70 moedas. Lembrando que o almoxarife ficou com uma moeda, quantas moedas cada marinheiros ganhou?

Cada marinheiro recebeu 23 moedas $(70=3 \times 23+1)$.

- Sabendo que o terceiro marinheiro tinha deixado dois terços na arca, tinha pego um terço e tinha jogado uma moeda ao mar, quantas moedas o terceiro marinheiro encontrou na arca antes da retirada?

Como 70 moedas são dois terços, então um terço são 35 moedas, ou seja, o terceiro marinheiro encontrou 106 moedas $(106=3 \times 35+1)$.

- Sabendo que a quantidade de moedas deixadas pelo segundo marinheiro foi a quantidade encontrada pelo terceiro marinheiro e que o segundo marinheiro também tinha deixado dois terços na arca, tinha pego um terço e tinha jogado uma moeda ao mar, quantas moedas o segundo marinheiro encontrou na arca antes da retirada?

Como 106 moedas são dois terços, então um terço são 53 moedas, ou seja, o segundo marinheiro encontrou 160 moedas $(160=3 \times 53+1)$.

- Sabendo que a quantidade de moedas deixadas pelo primeiro marinheiro foi encontrada pelo segundo marinheiro e que o primeiro marinheiro fez o mesmo processo 
dos outros dois, quantas moedas o primeiro marinheiro encontrou na arca antes da retirada?

Como 160 moedas são dois terços, então um terço são 80 moedas, ou seja, o primeiro marinheiro encontrou 241 moedas $(241=3 \times 80+1)$.

Assim, a quantidade de moedas que havia na arca inicialmente era de 241 MoEDAs.

Reflexão 10: Das 241 moedas colocadas inicialmente na arca, qual foi o destino delas?

Resolução: Basta somar as moedas que cada um dos marinheiros retirou da arca com as moedas que eles receberam do almoxarife, além das outras quatro moedas (três jogadas ao mar e uma que foi o pagamento do almoxarife):

- Primeiro marinheiro: $80+23=103$ moedas.

- Segundo marinheiro: $53+23=76$ moedas.

- Terceiro marinheiro: $35+23=58$ moedas.

- Jogadas ao mar: 3 moedas.

- Almoxarife: 1 moeda.

$$
103+76+58+3+1=241
$$

Algumas perguntas adicionais podem ser discutidas com os estudantes, como por exemplo:

- Supondo que nenhum dos marinheiros tivessem retirado moedas antes de serem repartidas pelo almoxarife, quantas moedas cada um receberia?

- Nessa situação, qual dos marinheiros receberiam mais moedas do que na situação inicial? E menos moedas? Algum marinheiro receberia a mesma quantidade de moedas?

- Ainda na suposta situação, quantas moedas receberia o almoxarife? Alguma moeda seria jogada ao mar? 
Após a socialização das ideias e às resoluções dessas atividades, os estudantes poderão fazer uma avaliação acerca de toda a atividade (críticas e sugestões poderão ajudar na avaliação feita pelo professor sobre a atividade, buscando aprimorar a aplicação da mesma).

Dessa forma, finalizamos esse capítulo com essas duas sugestões de atividades, baseadas na tendência metodológica conhecida como resolução de problemas. 


\section{Considerações Finais}

O estudo da matemática deve visar a sua aplicabilidade em situações do cotidiano. O aprendizado das quatro operações fundamentais, entre outros conteúdos da matemática, é feito através de algoritmos que facilitem a sua resolução e utilização. Todavia, frequentemente deixamos de relacionar essas operações com situações-problema. Com isso, a compreensão sobre o assunto fica prejudicada, visto que a simples mecanização dos algoritmos dessas operações não são eficientes.

Entre as quatro operações fundamentais, o método para realizar a divisão entre dois números, o Algoritmo da divisão de Euclides, é um dos mais complexos. A dificuldade encontrada por estudantes do sexto ano do ensino fundamental pode ser atenuada com a utilização de exemplos concretos, como os sugeridos nas atividades propostas. Dos livros pesquisados e utilizados em escolas da Secretaria de Estado de Educação do Distrito Federal, apenas em Iezzi ([?]) traz nos exercícios situações-problema relacionadas com a operação de divisão. Inclusive, em alguns de seus exercícios ([?], p. 44-45) utiliza-se a ideia da atividade do calendário exposta nessa dissertação, porém, não há uma construção progressiva da ideia utilizada (os exercícios apenas querem saber, por exemplo, qual dia da semana será daqui 100 dias, mas não há um passo a passo como o descrito nas atividades propostas). Nos livros de Neto ([?]), Giovanni ([?]), Dante ([?]), Souza ([?]), Andrini ([?]) e Bianchini ([?]), os exercícios, em sua maioria, visam a utilização do Algoritmo da divisão de Euclides sem uma problematização.

Esta dissertação, além de propor as atividades, contribui também para os estudos e formação continuada dos professores de matemática que atuam em sala de aula. Além disso, também desejamos que haja uma discussão mais efetiva entre os professores licenciados em matemática, que atuam nos anos finais do ensino fundamental, com os professores pedagogos, que atuam nos anos iniciais do ensino fundamental, acerca da metodologia usada no ensino da matemática. Podemos minimizar muitos problemas que surgem para os estudantes, em especial no $6^{\circ}$ ano do ensino fundamental, cujas 
mudanças metodológicas ocorrem significativamente.

A linguagem matemática formal utilizada para o profundamento do professor no tema claramente não deve ser usada em sala de aula com os estudantes. Essa adequação para uma liguagem mais simples e didática deve ser feita pelo professor, de forma que o estudante também possa entender os conceitos estudados na matemática científica.

As atividades propostas relacionam o Algoritmo da divisão de Euclides com situações reais, a fim de que possam ser facilmente inseridas no cotidiano dos estudantes. A primeira atividade relaciona o tema com o calendário, algo muito comum e de fácil assimilação. A segunda atividade utiliza uma história contada em um livro muito conhecido da área da matemática, e que também pode ser facilmente adaptado para uma situação real. Ambas as atividades foram adaptadas, pois costumam ser aplicadas para anos mais avançados da Educação Básica (ensino médio).

Uma sugestão para a aplicação das atividades é que sejam feitas em forma de oficinas, com uma duração aproximada de 2 horas para a atividade que envolve o calendário e de 3 horas para a atividade que envolve o problema dos três marinheiros. Para que as oficinas possam seguir os passos sugeridos, as turmas deverão ter no máximo 20 estudantes (podem ser aplicadas em turmas com mais estudantes, mas talvez o objetivo de discutir e mediar não seja alcançado).

Almejamos, com a aplicação dessas atividades, que os estudantes percebam a presença constante de problemas no dia-a-dia que são solucionados pelo Algoritmo da divisão de Euclides. O intuito é que, mesmo com a utilização do algoritmo, a compreensão do porquê da utilização não seja esquecida, afinal, a resolução de problemas estimula a criatividade e o desenvolvimento de interpretar situações matemáticas. De uma forma simples e estimulante as atividades sugeridas são conduzidas para que os estudantes descubram as resoluções através das discussões em grupo. Assim, além de compreender melhor o tema, o estudante poderá identificar e compartilhar outras situações em que o tema está posto. 


\section{Referências Bibliográficas}

[1] AABOE, Asger, Episódios da história da matemática, Coleção Fundamentos da Matemática Elementar, SBM, Rio de Janeiro, (1984).

[2] Andrini, Álvaro; VASCOnCellos, Maria José, Praticando Matemática, $6^{\circ}$ ano, Editora do Brasil - SP, 3a edição, (2012).

[3] BIANCHINI, Edwaldo, Matemática, 5a Série, Editora Moderna - SP, 6 a edição, (2006).

[4] BOCZKO, Roberto, Conceitos de Astronomia, Editora Edgard Blücher Ltda SP, (1984).

[5] BOYER, C.B., História da Matemática, Edgard Blücher, São Paulo (1974).

[6] BRASil, Secretaria de EducaÇão Fundamental, Parâmetros curriculares nacionais: terceiro e quarto ciclos do ensino fundamental: introdução aos parâmetros curriculares nacionais, MEC/SEF, Brasília - DF, (1998).

[7] DANTE, Luis Roberto, Tudo é matemática, 5 ${ }^{\mathrm{a}}$ série, Editora Ática - SP, $2^{\mathrm{a}}$ edição, (2008).

[8] Donato, Hernâni, História do Calendário, Série Prisma - Brasil, Editora da Universidade de São Paulo - SP, $2^{\text {a }}$ edição (1978).

[9] EVES, HowARD, Introdução à história da matemática, Record, Rio de Janeiro, (2014).

[10] FERREIRA, Jamil, A construção dos Números, Textos Universitários, SBM, Rio de Janeiro, $2^{\mathrm{a}}$ edição (2001). 
[11] GiOvanni, José Ruy Júnior; CASTRUCCI, Benedicto, A conquista da matemática, $6^{\circ}$ ano, Editora FTD - SP, $1^{\text {a }}$ edição, (2009).

[12] IEZZI, Gelson; DOlCE, Osvaldo; MACHAdo, Antonio, Matemática e Realidade, $5^{\mathrm{a}}$ Série, Editora Atual- SP, $5^{\mathrm{a}}$ edição (2005).

[13] LAS CASAS, RENATO, Disponivel em http://www.observatorio.ufmg.br/pas39.htm, 19.01.2016.

[14] LimA, Elon Lages, A Matemática de Ensino Médio, volume 1, SBM, Rio de Janeiro, (2006).

[15] Milies, C. P. E Coelho, S. P., Números: Uma introdução à Matemática, Editora da Universidade de São Paulo, São Paulo $3^{\text {a }}$ edição (2006).

[16] NETTO, Di Pierro, Matemática: conceitos e histórias, 5a série, Editora Scipione - SP, $5^{\text {a }}$ edição, (1998).

[17] NEVES, REgina DA Silva PinA, A divisão e os números racionais: uma pesquisa de intervenção psicopedagógica sobre o desenvolvimento de competências conceituais de alunos e professores, Brasília, 2008. Disponivel em http://repositorio.unb.br/, (01.06.2016).

[18] PAQUES, OtILIA, Disponivel em http://m3.ime.unicamp.br/recursos/1087, 17.01.2016.

[19] SANTANA, AnA Lucia, Malba Tahan, Disponivel em http://www.infoescola.com/biografias/malba-tahan/, (02.06.2016).

[20] ShOKRAnian, Salahoddin; SOARES, Marcus; GOdinho, Hemar, Teoria dos Números, Editora Universidade de Brasília, Brasília, 2a edição (1999).

[21] SOUZA, JoAmir Roberto De; PATARO, Patricia Moreno, Vontade de saber matemática, $6^{\circ}$ ano, Editora FTD - SP, $2^{\text {a }}$ edição, (2012).

[22] TAHAN, Malba, O Homem que Calculava, Editora da Unicamp, Campinas SP, 86 a edição (2004).

[23] ZORZAn, Adriana Salete Loss, Ensino Aprendizagem: Algumas Tendências na Educação Matemática, Rio Grande do Sul, (2007). 